\title{
Grammaticalization of the Particle away in English: A Cartographic Approach
}

\author{
Fumikazu NIINUMA* \\ Department of Nutritional Sciences, Morioka University, Takizawa, Iwate 020-0694, Japan
}

Received October 22, 2013; final version accepted February 14, 2014

\begin{abstract}
This study investigates the historical development of the particle away in English. Assuming the three-layered VP structure proposed by Ramchand (2008), and the Inner Aspect proposed by Travis (1994, 2010), Fujita and Matsumoto (2005), and Ogawa and Niinuma (2013), I argue that there are three positions available for the particle away: the directional away is located in Res, which is the lowest in the VP structure, the completive aspectual away is in Asp(completive), which is above Proc, and the continuative or iterative aspectual away is in Asp(continuative or iterative), which is above Asp(completive). The data from Corpus of Historical American English show that the continuative or iterative aspectual away has been concatenated with the activity verbs earlier than accomplishment verbs, which is compatible with the syntactic analysis of grammaticalization proposed by Roberts and Roussou (2003).
\end{abstract}

KEYWORDS: grammaticalization, the particle away, upward reanalysis, three-layered VP structure, Inner Aspect

\section{Introduction}

There has been a long debate concerning particle verbs in English (see Chomsky (1957), Bolinger (1971), Fraser (1976)). One of the intriguing issues about them is the word order between the particle and the direct object. Johnson (1991), Neeleman (1994), and Dehé (2002) argue that [Verb NP Particle] order is basic, and thus [Verb Particle NP] order is derived by the movement of the particle, or by rightward movement of the NP. On the other hand, some linguists including Hoekstra (1988), den Dikken (1995), and Svenonius (1996) argue that [Verb Particle NP] order is basic, so that the overt NP movement allows us to derive the structure [Verb NP Particle].

It has been recently argued in the literature (McIntyre (2011) and Los et al. (2012)) that valency reduction, which is a typical signal of grammaticalization, can be observed in the historical development of particles. For instance, Los et al. (2012) note that in Old English, the particles obligatorily took an argument, but as time goes by, it began to change from obligatory argument realization to optional argument realization. Finally, it began not to take any argument at all. Also, it has been pointed out that particles have lost their original meaning. For instance, the particle away, which has a directional meaning, may have the continuative meaning (cf. Jackendoff (1997a,b)). In other words, this change in meaning shows the semantic bleaching, which is an indication of grammaticalization. In fact, regarding the grammaticalization processes of the particle away, Ishizaki $(2010,2012)$ argues from the cognitive linguistic point of view that 'semi-idiomatic' construction, where the particle has an aspectual meaning (e.g. chatter away), is grammaticalized from the directional meaning.

However, the questions that immediately arise are 1) how they should be analyzed syntactically, i.e., Roberts and Roussou's (2003) upward reanalysis, and 2) what syntactic processes are involved in the grammaticalization of the particle away. According to Roberts and Roussou (2003:2), "grammaticalization involves the creation of new functional material, either through the reanalysis of existing functional material or through the reanalysis of lexical material." Furthermore, they claim "successive upward reanalysis along the functional hierarchy is thus how we define grammaticalization path (Roberts and Roussou (2003:202))."

In this paper, I will provide an answer to these questions. As for the first question, I will propose that the particle away can be realized in three positions depending on its meaning. More specifically, assuming the VP structure proposed by Ramchand (2008) and the existence of functional head within VP (cf. Travis (1994, 2010), Fujita and Matsumoto (2005), and Ogawa and Niinuma (2013)), away with the directional meaning is located in Res, away with the completive aspectual meaning is located in Asp(completive), and the continuative or iterative away is in Asp(continuative or iterative) just above Asp(completive), as shown in (1): ${ }^{1}$ 
(1) [InitP Init [AspP Asp(continuative or iterative) [AspP Asp(completive) [ProcP Proc

[ResP Res ] ] ]

Thus, the first half of this paper is devoted to the syntactic and semantic differences between the directional away and the continuative or iterative aspectual away. In order to do so, it is worth mentioning Ishizaki (2010, 2012), who argue that the particle away may function as a completive aspect, which is related to the fact that the particle does not take any argument. Following him, I will claim that the particle away has the two usages of the aspectual meaning: the completive meaning and the continuative or iterative meaning. The completive aspectual away is a transition period from the directional away to the continuative or iterative away. I will also argue that the completive away focuses on the result state, and the continuative or iterative away focuses on the action event. In this sense, the particle away can be realized in three positions: Res, Asp(completive) and Asp(continuative) or Asp(iterative). The proposed analysis conforms to the syntactic treatment of grammaticalization proposed by Roberts and Roussou (2003), since the realizations of the aspectual away in the Asp positions can be treated as an upward reanalysis from the Res head.

Finally, I will provide a data from Corpus of Historical American English (COHA) in order to support the present analysis. Focusing on the activity verbs such as puff, hammer, chew, gnaw, and nibble, and the accomplishment verbs such as eat, wash and burn, I will show 1) that the continuative or iterative away appears with the intransitive or transitive activity verbs earlier than with the accomplishment verbs, and 2) that the transitive verbs which allow the socalled conative construction occur with the continuative or iterative away earlier than the transitive verbs which do not.

The organization of this paper will be as follows. In the next section, I will briefly observe the analyses of Los et al. (2012) and Ishizaki $(2010,2012)$ regarding the historical development of the particle away. In section 3, I will observe syntactic and semantic properties of the directional away and the continuative or iterative aspectual away, and discuss the existence of the completive aspectual away. In section 4, I will propose a syntactic analysis of the particle away and explain the historical development of the particle. In section 5, I will provide the corpus data, which constitutes a piece of evidence for the present analysis concerning the historical development of the particle away. In section 6, I will summarize the paper and discuss the implications of the proposed analysis.

\section{Historical Development of away in English}

It is a well-known fact that the particle away has developed from the word onweg, which consisted of the preposition $o n$, which has changed to the prefix $a$-, and the noun way (see Nagano (this volume) for the analysis of the prefix $a$ - in English). It was a native adverb in English and has been used to describe a direction of physical motion as well as a direction of metaphorical motion since OE (see Ishizaki $(2010,2012)$ ).

Los et al. (2012) point out that in OE, the particles, including away, appeared in a preverbal position, and they functioned as a secondary resultative predicate, so that they projected themselves, and took an internal argument. However, the particles in ME period began to be located in a post-verbal position, as the word order in ME began to change from SOV to SVO. In addition, the meaning of the particle had changed from resultatives to some other meanings, such as idioms as well as aspectual meaning, which Los et al. (2012) argue is a type of lexicalization (see also Brinton (1988), Hiltunen (1983), and Tanabe (1999)). Based on the meaning shift of the particles, Los et al. (2012) argue that they gradually began to take an internal argument optionally, and finally not to take any argument at all.

On the other hand, Niwa $(1991,1995)$ notes that the particle away in the Old English period occurred only with two types of verb, namely DRIVE type and GO type. The relevant examples are shown below:

(2) a. from wuldre his onweg adrifene sind

'(men) are driven away from his glory'

b. se dæl pe pær aweg com wurdon on fleame generede 'the remnant that have escaped there were saved by flight'

(The Vesparian Psalter: 48 15/Niwa (1995: 1))

(The Saxon Chronicle: 89487 30/ibid.: 5)

(Ishizaki (2010, 2012) investigated the distribution of the particle away using the Corpus of Early Modern English Correspondence Sampler, and points out that in the early Modern English period, the particle away is extended to combine with other verbs, and he provides the typical combination of verbs in this period.

(3) take away, go away, send away, run away, come away, cast away, call away, put away, carry away, march away, wear away, convey away

The relevant examples with away, which are all taken from Ishizaki (2012a: 76), are illustrated below:

(4) a. ... and toke a rusty swerd and smote of his heddle withyn half a doseyn strokes, and toke awey his gown of russette 
'... and [he] took a rusty sword, and smote off his head within half a dozen strokes, and took away his gown of russet'

(William Lomnor, 450: 30-32)

b. The Duck ys men rensackyd the church and bare a-way all the gode that was lefte there 'The Duke's men ransacked the church and bear away all the good that was left there'

(Margaret Paston, 196: 34-35)

Interestingly, Ishizaki (2012: 199) points out that in this period, away may gain the aspectual meaning (completive), and the following example may be ambiguous between the directional meaning and the (completive) aspectual meaning:

(5) ... Sir Thomas Fairfax also went away before I could certifie; and Sir Edward (who hathe taken great paines in this matter) was in the contrie, I didn't know where, nor when he would retourne;

(1602, A Matthew Hutton 1, 164-165/Ishizaki (1999: 199))

It seems to me that it is the beginning of the appearance of the particle away which does not take any argument, in the sense of Los et al. (2012), even though it is not clear whether went away in (5) is an example of the completive aspectual meaning of away, because it can also be considered as a resultative meaning. Furthermore, according to Ishizaki (2010, 2012), this completive aspectual meaning of away, which seems to be a natural extension of its resultative meaning, has developed to the iterative or continuative aspectual meaning of away in Present-day English:

(6) a. He kept writing away at his books.

b. Ivan worked away.

(Bolinger (1971))

(Jackendoff (1997))

Akimoto (1999: 223) investigated the token and type frequency of away in later Modern English (the $18^{\text {th }}$ and $19^{\text {th }}$ centuries) and points out that it was combined with the following verbs, as listed in (7). The relevant examples are shown in (8):

(7) a. $18^{\text {th }}$ century

take away, send away, die away, give away,

b. $19^{\text {th }}$ century

go away, run away, die away, pass away, take away

(8) a. Miss Leigh said she had sent away her chair and servants with intent of staying till 9 o'clock

b. Dr Aumont went away $-\&$ the Coast was clear

(Letters [Montagu]: 65/Akimoto (1999: 224))

(Letters [Burney]: 201/ibid.)

To summarize this section, the particle away has developed from the resultative secondary predicates, which take an internal argument, to the completive and continuative or iterative aspectual meaning, which does not take any. In the remainder of this section, I will investigate the nature of the directional away and the aspectual away in Present-day English.

\section{Syntactic and Semantic Properties of the Particle away}

In this section, I will observe the syntactic and semantic properties of the particle away, and show that the directional away and the continuative or iterative aspectual away should be distinguished syntactically. I will also discuss the existence of the completive aspectual away, following Ishizaki (2010, 2012).

\subsection{Directional away}

According to Shimada (1985), the directional away combines with so-called motion verbs, and the directional away metaphorically gained the 'removal' meaning from the directional meaning. The relevant examples are shown below:

(9) intransitive verbs

back away, bolt away, break away, go away, run away, slip away, walk away

(10) transitive verbs

beat away, break away, burn away, cut away, ease away, pull away, wash away 
Let us now consider whether the intransitive verbs above are unergatives or unaccusatives. It is well-known that even unergative verbs such as run or walk may show the unaccusative properties if we add the PPs that denote an end point of the action (cf. Talmy (1985), Mateu (2002), and Zubizarreta and Oh (2007)). The question is whether the directional away can function like the PPs. McIntyre (2011) tries to answer this question and argues that the intransitive verbs in (9) should be unaccusative verbs. One of the tests comes from past participles in English. Unaccusative past participles can be used as nominal modifiers with active meaning, while unergative past participles cannot, as shown in (11). Based on this test, the grammatical examples in (12) indicate that the phrasal verbs in (9) should be unaccusative verbs.

(11) a. unaccusative: the melted snow, the departed guests, the fallen soldiers

b. unergative: *the shouted victim, *the slept child, *the hesitated leader

(12) a. the backed away boy

b. the run away boy

c. the gone away boy

d. the walked away boy

(cf. http://www3.unine.ch/files/content/sites/andrew.mcintyre/files/shared/mcintyre/3.argstr.genf.pdf)

If we try to generalize the properties of the phrasal verbs in (9) and (10), we can say that the phrasal verbs with the directional away are unaccusative verbs or transitive verbs, which require an internal argument.

One may wonder why this should be so. Recall that resultatives must be object-oriented (see Levin and Rappaport (1995:34)). Furthermore, Los et al. (2012) argues that particles in Old English are all resultatives, and that particles in Old English must have an argument. If their arguments are on the right track, one can conclude that the directional away is a type of secondary resultative predicates, which require an argument.

McIntyre (2004) argues that in resultative constructions, the internal argument must be licensed by a secondary predicate, not a main verb. As is often pointed out in the literature (cf. Nishiyama (1998) and McIntyre (2004)), the addition of the resultative predicate may add the direct object in some cases, which cannot be licensed by a verb itself, as shown in (13). With this in mind, let us consider the examples in (14). This fact can be explained in the same way as the fact that the unergative verbs can have an internal argument by adding the resultative secondary predicate, as in (13):

(13) a. ${ }^{*}$ The jogger ran the pavement.

b. The jogger ran the pavement thin.

(14) a. The dog barked (*me).

b. The dog barked me away.

In addition, it is a well-known fact that the internal argument which otherwise cannot be selected by a verb can be realized by adding a secondary predicate. For instance, the internal argument the cellar cannot be licensed by the verb drink. However, it becomes possible if we add the resultative predicate $d r y$ to the sentence, as shown in (15). The same effect can also be observed in (16):

(15) a. *John drank the cellar.

b. John drank the cellar dry.

(McIntyre (2004))

(16) clear $\{$ up / away\} (the dishes) (cf. clear*(the dishes))

(Cappelle (2005))

Therefore, it is now safe to conclude that the directional away obligatorily bears an internal argument.

\subsection{Continuative or Iterative away}

The continuative or iterative aspectual use of away with verbs has been touched upon by Bolinger (1971: 104-50, Brinton (1985: 165-67), Jackendoff (1997: 539-40; 2002: 77-78), McIntyre (2001b: 132) and Rice (1999: 237-39), and many more. According to Brinton (1985) and Ishizaki (2010, 2012), the aspectual away expresses continuation or iteration, so that the whole event refers to an atelic event (see also Shimada (1985)). Jackendoff (1997: 541) also points out that "aspectual away emphasizes atelicity." Furthermore, one of the typical properties of the continuative or iterative aspectual away is that the verbs must be intransitives. The relevant examples are given below:

(17) a. Are you all knitting away furiously for Christmas?

b. .... a traditional fairground music organ playing merrily away.

c. So, here I sit, laboring away like the dutiful little web designer I am. 
d. I realised he was actually Tony Blair - with the camera-rats still filming away at him $-\ldots$

e. ... and the only sounds Sam could hear was the rain, her latest favourite album beating away casually on her mini-hi-fi, and a ginger cat purring away, ...

(Cappelle (2005))

Also Shimada (1985) notes that the gerundive forms of verbs with the aspectual away sometimes appear in the complement position of the verb keep, as shown below:

(18) a. I can't understand you if you keep jabbering away like that.

b. He keeps swigging away at that bottle of brandy.

(Shimada (1985: 138))

The following contrast shows that the continuative or iterative aspectual away differs from the directional away in that it can license the durative PP modifiers, not the time span PP modifiers:

(19) a. I whittled away at my excessive pounds $\left\{\right.$ for $/ *^{*}$ in $\}$ two months (aspectual away)

b. I whittled away my excessive pounds $\{$ in $/ *$ for $\}$ two months (directional away).

(Cappelle (2005))

What is interesting for our concern is the fact that the continuative or iterative aspectual away cannot have a direct object, but instead it can take PPs, a type of conative construction. The relevant examples are shown in (20): ${ }^{2}$

(20) a. He was scrubbing away at the floor. (cf. He was scrubbing the floor)

b. I was typing away at my report. (cf. I was typing my report)

c. She smoked away at her cigarette. (cf. She smoked her cigarette)

This fact is related to the fact that the continuative or iterative aspectual away must co-occur with intransitive verbs, which cannot take an internal argument by definition.

Let us now consider what type of verbs can appear with the continuative or iterative aspectual away. Here is the list of verbs provided by Shimada (1985), using the verb classes discussed by Levin (1993).

(21) a. Verbs of social interaction: argue, bargain

b. Verbs of contact by impact: bang, fire, flail, hammer, kick, pound, scratch, shoot, tap

c. Verbs of emission: blaze, burn, buzz, glow, plod, puff, rattle, shine, shimmer

d. Verbs involving the body: blink, breathe, chip, gasp, gobble, laugh, sob, throb, twitch, yawn

e. Verbs of creation and transformation: boil, chip, churn, dig, grind, peg, plug, saw, scrape, slave, slog, treadle, wash, work

f. Verbs of communication: chat, drone, gabble, gibber, howl, jabber, jaw, mumble, nag, prattle, sing, spin, squabble, talk

g. Verbs of ingesting: chew, drink, eat, feast, gnaw, guzzle, munch, nibble, peck, pick, swig

h. Verbs of motion: file

i. Psych verbs: fret

j. Verbs of perception: gaze

k. Verbs of change of possession: grab

1. Image creation verbs: dream, scribble

$\mathrm{m}$. Verbs of removing: rub, scrub

As is clear from the verbs above, they are mainly intransitive verbs, which denote activity. In addition, the verbs such as argue or gaze takes PP as a complement. However, there are some instances of transitive verbs, such as verbs of contact by impact and verbs of ingesting, which appear to be problematic.

Let us first consider verbs of contact by impact. According to Levin (1993), they typically allow so-called conative construction, as given in (22)-(23):

(22) a. The police are hammering the door.

b. The police are hammering at the door.

(23) a. They shoot the elephant.

b. They shoot at the elephant.

In this construction, prepositions such as at intervene between a verb and the direct object, so that the verb looks like an 
intransitive verb. Interestingly, it has been noted in the literature that the conative construction is compatible with the durative adverbials, as illustrated below:

(24) a. *John slashed the painting for an hour.

b. *John ate the pizza for an hour.

c. *John drank a mug of beer for an hour.

(McDonald (2008: 201))

(25) a. John slashed at the painting for an hour.

b. John ate at the pizza for an hour.

c. John drank from a mug of beer for an hour.

In this sense, the conative construction turns accomplishment verbs to activity verbs.

So far, the verbs which are compatible with the continuative or iterative away are restricted to activity verbs. However, one may wonder whether the following examples may constitute a piece of counter-evidence for the observation because the verbs below seem to have the direct object:

(26) Do you want me to talk /recite (my lesson) / tell this joke) or not? Sure, talk / recite (it) / tell (it) away!

However, it is quite doubtful whether the direct object it in (26) can be an argument. In fact, Nagano (2007; 132) argues that the major function of the empty object it is to pretend that the verb looks like a transitive verb. This means that the empty object it has no semantic function at all, so that the verb itself is an intransitive verb even though the empty object it is added to the sentence.

\subsection{Interim Summary}

To summarize this subsection, we have shown the three syntactic and semantic properties of the continuative or iterative aspectual away: 1) it is compatible only with intransitive verbs, 2) the whole event denotes an activity, hence atelic, and 3) it can have PPs, instead of an internal argument.

What we have found from the observations above is the followings:

(27) a. away with the directional meaning requires an argument.

b. away with the continuative or iterative aspectual meaning cannot have any argument.

\subsection{Completive Aspectual away}

Finally, I would like to point out that the particle away also has the completive aspectual meaning. As noted above, Ishizaki (2012a, b) points out that the particle away may have the completive aspect. Furthermore, Bybee, Perkins, and Pagliuca $(1994,54)$ also note that completive aspect in English can be expressed through particles including up (eat versus eat up), out (dry versus dry out), and away (fly versus fly away) (see also Emonds (1985), Jackendoff (1997a, 2002)). It seems to me that the completive aspectual away shares some properties with the directional away, in that they both are compatible with accomplishment verbs, which denotes a result state. Furthermore, they have almost identical meanings: for instance, went away in (5) could mean either that somebody went to a certain direction (directional away) or that we couldn't see him because he was gone (completive away). Thus, it could be possible to assume the following scenario. In a sequence of [V NP away], when the particle away takes an internal argument, the sequence is classified as [V [NP away]]. On the other hand, when the particle does not have to take any argument, the sequence began to be categorized as [[V NP] away], in which the completive aspectual away has developed. ${ }^{3}$

Therefore, I assume that the particle away is also used as a completive aspect marker (see Svenonius (2012) for the completive particle up in English).

\section{An Analysis}

In this section, I will offer a syntactic analysis of the particle away under the Cartographic approach (Cinque (1999, 2006)) with the analysis of the existence of Inner Aspect within VP (see Travis (2010), Fujita and Matsumoto (2005) and Ogawa and Niinuma (2013)).

\subsection{Proposals}

One of the goals of the cartographic approach is to explain the interaction between syntax and semantics. In this approach, every single feature of a clause is represented in the cartographic architecture, including its semantic nuances and the lexical item content specifications. Thus, abstract semantics, such as mood, aspect, tense etc., are considered to 
be a functional head in the syntactic architecture.

Following the cartographic spirits, Ramchand (2008) proposes that a VP can be divided into three maximal projections, Init(iate)P, Proc(ess)P, and Res(ult)P. The syntactic characterizations of these three maximal projections are as follows:

(28) a. InitP represents the outer causational projection and is responsible for introducing the external argument. (Ramchand (2008: 39))

b. ProcP is the heart of the dynamic predicate, since it represents change through time, and it is present in every dynamic verb. (ibid.: 40)

c. The ResP only exists when there is a result state explicitly expressed by the lexical predicate. (ibid.: 40)

d. The head of ResP is realized by the overt verb which can take a simple locational PP as its complement, and a DP in its specifier functions as the subject of the predicative PP. (ibid.: 75)

The second important assumption is the existence of Aspect head. According to Cinque (1999, 2006), there are so many Aspect heads in a syntactic structure, and they are ordered depending on the semantics of the Aspect head. More importantly, these Aspect heads are located above VP. On the other hand, Travis (1994, 2010), Fujita and Matsumoto (2005), and Ogawa and Niinuma (2013) argue that an Aspect head may be located within VP. One of the motivations for the existence of the Aspect head within VP is the fact that a different morphological Case or preposition on a Location DP or Theme DP affects the telicity of the event denoted by the verb. For example, we can say that the event in (29a) is telic and the event in (29b) is atelic, because of the prepositions in these examples. Also, it is a well-known fact that in Finnish, the different morphological Case realization changes the telicity of the event denoted by the verb, as in (30). If we assume that the event delimiter moves to [Spec, AspP] and undergoes feature checking with Asp, it is not surprising that a DP or a PP, which plays the same grammatical function, shows a different morphological realization.

(29) a. Mary ran towards the store for 3 hours $/{ }^{*}$ in 3 hours.

b. Mary ran to the store in 3 hours $/{ }^{*}$ for 3 hours.

(Travis (2010: 110))

(30) a. Anne rakensi talo-a tunni-n/*tunii-ssa.

Anne build house-Part hour-Acc/*hour-inessive

'Anne was building a/the house for an hour/*in an hour.'

b. Anne rakensi talo-n vuode-ssa/*vuode-n.

Anne build house-Acc year-inessive /*year-Acc

'Anne built a/the house in a year/*for a year.'

(Ritter and Rosen (2001: 436))

Thus, in this paper, I will assume Ogawa and Niinuma's (2013) VP structure where an Aspect head is located above ProcP and below InitP. More specifically, there are two Asp heads related to the completive meaning or the continuative or iterative meaning. Thus, the structure I will propose is illustrated in (31):

(31) [InitP Init [AspP Asp(continuative or iterative) [AspP Asp(completive) [ProcP Proc [ResP Res ]]]]

(cf. Ogawa and Niinuma (2013))

Given this, I will propose that the particle away with the three different meanings is realized in three different positions, as shown below:

(32) a. the directional away is located in Res and it takes an argument NP.

b. the completive aspectual away is located in Asp(completive).

c. the continuative or iterative aspectual away is located in Asp(continuative or iterative).

With them in mind, let us consider the syntactic structures of the following sentences:

(33) a. John ran away (directional away)

[ProcP John 1 run [ResP $t_{1}$ Res(away)]

b. The plane flied away (completive away)

[Asp(completive) away [ProcP the plane 1 fly [ResP $t_{1}$ Res]]

c. Mary knitted away (continuative or iterative away)

[InitP Mary [AspP(continuative or iterative) away [ProcP knit]]] 
In (33a), the particle away is realized in Res, and it takes an argument John. In (33b), the particle away is promoted to the Asp position, so that it does not take any argument. However, it is compatible with the ResP. The particle in (33c) is realized in the Asp head which is located in a position between Asp(completive) and InitP, and it can modify the action event, not the result state.

According to Ramchand (2008), resultative secondary predicates are located in a very low position within the VP structure, which forms a small clause with an argument. Thus, it would not be so surprising that the directional away and the resultative secondary predicates are located in the same position. Also, as suggested by their names, the completive and continuative or iterative aspectual away are "aspectual," so that it is reasonable to consider that they are located in Aspect head positions.

An important consequence of this analysis is that stative verbs cannot co-occur with the particle away, no matter what meaning it has. We can naturally account for this for two reasons. Let us first consider the directional away and the completive away. According to Ramchand (2008), the VP structure for stative verbs is just ResP, so that there is no causer or agent in a sentence. As discussed in the previous section, the directional away and the completive aspect away are only compatible with Accomplishment, which requires a result state, and thus the stative verbs cannot co-occur with the directional away. On the other hand, the stative verbs cannot co-occur with the continuative or iterative aspectual away either because the particle in this usage requires to combine with activity verbs. In the three-layered VP structure proposed by Ramchand (2008), activity denotes just InitP and ProcP, excluding ResP. That is why stative verbs and the particle away cannot be combined to form a phrasal verb.

\subsection{Grammaticalization of away}

As shown in the previous section, the directional away requires the internal argument, but the continuative or iterative aspectual away does not. This means that the directional away is compatible with accomplishment verbs, but the continuative or iterative aspectual away is compatible with activity verbs. It seems that they are very different. However, many linguists including Ishizaki (2010, 2012) and Los et al. (2012) argue that the continuative or iterative aspectual away has been grammaticalized from the directional away. The question is how the continuative or iterative aspectual away has developed. In this section, I will consider a possible explanation for this.

Niinuma (2013) argued that unspecified object deletion plays a crucial role in explaining the grammaticalization of the particle away. However, as pointed out by an anonymous reviewer, it is implausible because of the fact that the verb eat, for instance, is used as an intransitive verb even in the $9^{\text {th }}$ century, according to the OED.

Recall that Ishizaki $(2010,2012)$ notes that the particle away gained the completive aspectual meaning, so that the following sentence is ambiguous between the directional meaning and the completive meaning:

(34) ... Sir Thomas Fairfax also went away before I could certifie; and Sir Edward (who hathe taken great paines in this matter) was in the contrie, I didn't know where, nor when he would retourne;

(1602, A MATTHEW HUTTON 1, 164-165/Ishizaki (1999: 199))

Thus, it is quite natural to think that around the $17^{\text {th }}$ century the particle away has gained the (completive) aspectual meaning. Note that the internal argument was still present in (34), where the verb is an unaccusative verb. Then, the question is how the particle away has developed in order to be combined with activity verbs. It seems to me that the change from the directional (or completive) away, which is combined with transitive or unaccusative verbs, to the iterative or continuative away, which is compatible with intransitive activity verbs is too huge, and there must be a gradual step from the directional away to the continuative or iterative away.

Therefore, I propose the grammaticalization of the particle away proceeds as follows:

(35) a. The particle away had the directional meaning, which obligatorily takes an internal argument.

b. The particle gained the completive aspectual meaning, as the particle did not take an internal argument.

c. The particle gained the continuative or iterative aspectual meaning and thus it can combine with activity verbs.

If this analysis is on the right track, then it will predict the following two things:

(36) a. The continuative or iterative away appears with the intransitive or transitive activity verbs earlier than with the accomplishment verbs.

b. The transitive verbs which allow the conative construction occurs with the continuative or iterative away earlier than the transitive verbs which do not.

Let us now examine in more detail what (36) mean. In (36a), the fact that the continuative or iterative away is not compatible with the direct object implies that it can easily be combined unergative intransitive verbs. In addition, since the continuative or iterative away modifies the action, it would also be easy to be concatenated with transitive activity verbs. On the other hand, since the accomplishment verbs requires the internal argument, it would be much harder, if not impossible, to combine with the completive or iterative away. ${ }^{5}$ 
Let us finally discuss (36b). As noted in (20), the continuative or iterative away co-occurs with the conative construction. As discussed by Levin (1993) and Kageyama (1996), the conative construction seems to be found with contact and motion verbs such as hit, cut, and hammer, in addition to ingesting verbs such as eat, gnaw and nibble. Furthermore, as discussed in (25), the conative construction focuses on the action itself, rather than the resultant state, so that 'for X-time' adverbials are properly licensed. Thus, if an accomplishment verb which does not allow the conative construction tries to be found with the conative construction, it must first be concatenated with the continuative or iterative away, which is more costly than the accomplishment verbs which allow the conative construction. Thus, we would expect that the verbs which are compatible with the conative construction is found with the continuative or iterative away earlier than the verbs which do not.

The next section is devoted to examine the predictions in (36).

\section{Corpus Data}

In order to investigate whether the predictions discussed in the previous section is correct, I used the Corpus of Historical American English (COHA). COHA is created by Brigham Young University, which is the largest structured corpus of historical English. It allows us to search quickly and easily more than 400 million words of text of American English from 1810 to 2009. Therefore, it is suitable for the linguistic research on the historical development of words, phrases, and so on.

In order to investigate the historical development of the particle away, I examined the following three things: the total frequencies of the occurrence of a verb, the frequencies of the occurrence of the transitive and intransitive usages (unspecified object deletion) of 'verb + away,' and the frequencies of occurrence of 'verb + away at.' Finally, I searched these cases with activity verbs such as puff, hammer, chew, gnaw, and nibble, as well as accomplishment verbs such as eat, wash and burn.

One caveat is in order. Notice that the sequence 'verb + away' does not necessarily indicate the continuative or iterative aspectual usage of the particle away. For instance, when a verb is unaccusative, then the particle away in the context of 'verb + away' can be analyzed as the directional away and the completive aspectual away, as well as the continuative or iterative away. Furthermore, the careful examination is needed even when the verb is transitive, because of the possibility of unspecified object deletion. It has been pointed out in the literature (cf. Rice (1988), Goldberg (2001), and references therein) that unspecified object deletion tends to occur in imperatives and conjuncts, which tends to focus on the action itself, rather than the result state. ${ }^{6}$ The relevant examples are shown in (37)-(38):

(37) a. I'll lead and you follow. (Dixon (1991: 289))

b. Billy Jo washed and Bobby Jo dried. (Rice (1988: 206))

(38) a. Pull lid to open.

b. Don't heat up.

(cf. Carpelle (2005))

Thus, in this paper, when 'verb + away' appears in the context containing the conjunct or in the imperative form, I regarded it as an instance of the unspecified object deletion, rather than the continuative or iterative aspectual away. On the other hand, when the particle away appears in the context where the preposition such as at or on follows the particle away, it is regarded as an instance of the continuative or iterative away.

\subsection{Overview}

Let us first consider how often the verb sequences 'verb + away' and 'verb + away at' are used historically. The following tables indicate the frequencies of the occurrence of the 'verb + away' and 'verb $+a w a y$ at', respectively:

(39) The frequency of the occurrence of verb $+a w a y^{7}$

\begin{tabular}{lcccccccccc}
\hline SECTION & 1810 & 1820 & 1830 & 1840 & 1850 & 1860 & 1870 & 1880 & 1890 & 1900 \\
\hline FREQ & 380 & 2346 & 4732 & 6205 & 7181 & 8027 & 9758 & 10096 & 9485 & 10933 \\
\hline PER MIL & 321.71 & 338.67 & 343.53 & 386.64 & 435.96 & 470.66 & 525.69 & 496.95 & 460.42 & 494.76 \\
\hline SECTION & 1910 & 1920 & 1930 & 1940 & 1950 & 1960 & 1970 & 1980 & 1990 & 2000 \\
\hline FREQ & 10959 & 11518 & 10648 & 9857 & 9809 & 9208 & 9301 & 9974 & 11609 & 12285 \\
\hline PER MIL & 482.76 & 448.98 & 432.8 & 404.84 & 399.64 & 384.03 & 390.55 & 393.98 & 415.47 & 415.49 \\
\hline
\end{tabular}


(40) The frequency of the occurrence of verb + away at

\begin{tabular}{lcccccccccc}
\hline SECTION & 1810 & 1820 & 1830 & 1840 & 1850 & 1860 & 1870 & 1880 & 1890 & 1900 \\
\hline FREQ & 0 & 19 & 64 & 81 & 103 & 128 & 151 & 133 & 154 & 159 \\
\hline PER MIL & 0 & 2.74 & 4.65 & 5.05 & 6.25 & 7.51 & 8.13 & 6.55 & 7.48 & 7.2 \\
\hline SECTION & 1910 & 1920 & 1930 & 1940 & 1950 & 1960 & 1970 & 1980 & 1990 & 2000 \\
\hline FREQ & 161 & 184 & 174 & 159 & 207 & 214 & 198 & 193 & 205 & 219 \\
\hline PER MIL & 7.09 & 7.17 & 7.07 & 6.53 & 8.43 & 8.93 & 8.31 & 7.62 & 7.34 & 7.41 \\
\hline
\end{tabular}

Notice that in (40) there are some examples which are totally irrelevant to the conative construction, such as at all, at once, at a rate, and so on, and thus we have to figure out the number of the conative construction. The following table shows the frequencies of the occurrence of $\mathrm{V}+$ away at with the conative construction:

(41) The frequency of the occurrence of $\mathrm{V}+$ away at with the conative construction

\begin{tabular}{lcccccccccc}
\hline SECTION & 1810 & 1820 & 1830 & 1840 & 1850 & 1860 & 1870 & 1880 & 1890 & 1900 \\
\hline FREQ & 0 & 6 & 25 & 33 & 49 & 56 & 69 & 66 & 68 & 69 \\
\hline PER MIL & 0 & 0.86 & 1.81 & 2.06 & 2.97 & 3.28 & 3.72 & 3.25 & 3.3 & 3.12 \\
\hline SECTION & 1910 & 1920 & 1930 & 1940 & 1950 & 1960 & 1970 & 1980 & 1990 & 2000 \\
\hline FREQ & 93 & 101 & 105 & 91 & 144 & 141 & 137 & 141 & 154 & 147 \\
\hline PER MIL & 4.1 & 3.94 & 4.27 & 3.74 & 5.87 & 5.88 & 5.75 & 5.57 & 5.51 & 4.97 \\
\hline
\end{tabular}

Even though the number of the sentences in the early $19^{\text {th }}$ century on the COHA is relatively small, we can see that the $\mathrm{V}+$ away at with the conative construction began to be used in the early $19^{\text {th }}$ century, and the number of the occurrence has increased since then. What is important for our concern is that all of the examples found in $1820 \mathrm{~s}$ contain activity verbs, as shown in (42):

(42) a. - no earthiness in the colour of the one - nothing mortal in the smooth melody of the other; yet fainting away at their approach - O, men will deceive themselves!

(1823, Errata)

b. It was not the face of a bride. Never,' said Lucia - Archibald reeled away at the sound; but, instantly recovered himself, and walked apart with us.

(1823, Seventy-six, volume 2)

c. Captain Rodman too, did famously; but the major! - well - Guns! how he rattled away at' em! - hey no quarter - none! - It soon became a race - whoop!

d. Master Jemmy had just discovered that the fountain of her beauty was near to him - and he was puffing away at it - hands and feet, like a fine fellow - when I arose, and looked upon him, leaning over the mother and child, with a feeling such as a father and husband only, can experience.

e. she added, turning to the servant, who was lying stretched out on the floor at the foot of the bed, "get up, and undress me; I have been dying with sleep this half hour, while papa was prosing away at me.

(1824, Redwood)

f. The young Mohican darted away at the suggestion, and the scout had hardly done speaking, before the former raised a cry of success from the margin of the forest.

(1826, The Last of the Mohicans)

Given these backgrounds, I will carefully examine the verbs such as puff, hammer, chew, gnaw, nibble, eat, wash, and burn for the rest of this section.

\subsection{Activity Verbs}

\subsubsection{Puff}

Let us first consider the verb puff. The reason why this verb is chosen is because the word sequence puff away at is one of the examples that appear in 1820s, as shown in (42). The frequencies of the occurrence of puff away and puff away at are shown below: 
(43) The frequency of the occurrence of puff away

\begin{tabular}{lcccccccccc}
\hline SECTION & 1810 & 1820 & 1830 & 1840 & 1850 & 1860 & 1870 & 1880 & 1890 & 1900 \\
\hline FREQ & 1 & 3 & 9 & 16 & 9 & 3 & 12 & 13 & 6 & 10 \\
\hline PER MIL & 0.85 & 0.43 & 0.65 & 1 & 0.55 & 0.18 & 0.65 & 0.64 & 0.29 & 0.45 \\
\hline SECTION & 1910 & 1920 & 1930 & 1940 & 1950 & 1960 & 1970 & 1980 & 1990 & 2000 \\
\hline FREQ & 6 & 14 & 13 & 11 & 8 & 5 & 6 & 7 & 6 & 5 \\
\hline PER MIL & 0.26 & 0.55 & 0.53 & 0.45 & 0.33 & 0.21 & 0.25 & 0.28 & 0.21 & 0.17 \\
\hline
\end{tabular}

(44) The frequency of the occurrence of puff away at

\begin{tabular}{lcccccccccc}
\hline SECTION & 1810 & 1820 & 1830 & 1840 & 1850 & 1860 & 1870 & 1880 & 1890 & 1900 \\
\hline FREQ & 0 & 1 & 1 & 2 & 5 & 2 & 6 & 5 & 4 & 4 \\
\hline PER MIL & 0 & 0.14 & 0.07 & 0.12 & 0.3 & 0.12 & 0.32 & 0.25 & 0.19 & 0.18 \\
\hline SECTION & 1910 & 1920 & 1930 & 1940 & 1950 & 1960 & 1970 & 1980 & 1990 & 2000 \\
\hline FREQ & 4 & 1 & 4 & 5 & 4 & 1 & 1 & 1 & 0 & 1 \\
\hline PER MIL & 0.18 & 0.04 & 0.16 & 0.21 & 0.16 & 0.04 & 0.04 & 0.04 & 0 & 0.03 \\
\hline
\end{tabular}

Even thought its low frequency of the usage puff away at, we can see that that the continuative or iterative aspectual away has been used since the early $19^{\text {th }}$ century. Some other examples involving the continuative or iterative aspectual away are shown below:

(45) a. He is getting out of sorts at the delay rather rapid, a body would guess, by the manner he is puffing away at his old comforter there.

(1839, The Green Mountain Boys)

b. The conversation which we have briefly written occupied but a few moments, and it was evident from the manner of the parties, that they thoroughly understood each other. Peter puffed away at his cigar, holding the card turned to the light and endeavouring to read the inscription with one eye closed.

(1849, Memoirs of a Preacher)

\subsubsection{Hammer}

The verb hammer is also an activity verb, which appears in the early $19^{\text {th }}$ century with the verb sequence hammer away at. The frequencies of the occurrence of hammer away and hammer away at are shown in (46) and (47), respectively.

(46) The frequency of the occurrence of hammer away

\begin{tabular}{lcccccccccc}
\hline SECTION & 1810 & 1820 & 1830 & 1840 & 1850 & 1860 & 1870 & 1880 & 1890 & 1900 \\
\hline FREQ & 0 & 0 & 5 & 3 & 6 & 6 & 9 & 6 & 14 & 4 \\
\hline PER MIL & 0 & 0 & 0.36 & 0.19 & 0.36 & 0.35 & 0.48 & 0.3 & 0.68 & 0.18 \\
\hline SECTION & 1910 & 1920 & 1930 & 1940 & 1950 & 1960 & 1970 & 1980 & 1990 & 2000 \\
\hline FREQ & 8 & 15 & 18 & 13 & 19 & 19 & 14 & 16 & 15 & 14 \\
\hline PER MIL & 0.35 & 0.58 & 0.73 & 0.53 & 0.77 & 0.79 & 0.59 & 0.63 & 0.54 & 0.47 \\
\hline SECTION & 1810 & 1820 & 1830 & 1840 & 1850 & 1860 & 1870 & 1880 & 1890 & 1900 \\
\hline
\end{tabular}

(47) The frequency of the occurrence of hammer away at

\begin{tabular}{lcccccccccc}
\hline SECTION & 1810 & 1820 & 1830 & 1840 & 1850 & 1860 & 1870 & 1880 & 1890 & 1900 \\
\hline FREQ & 0 & 0 & 3 & 3 & 4 & 1 & 4 & 1 & 5 & 2 \\
\hline PER MIL & 0 & 0 & 0.22 & 0.19 & 0.24 & 0.06 & 0.22 & 0.05 & 0.24 & 0.09 \\
\hline SECTION & 1910 & 1920 & 1930 & 1940 & 1950 & 1960 & 1970 & 1980 & 1990 & 2000 \\
\hline FREQ & 7 & 7 & 12 & 7 & 10 & 9 & 7 & 10 & 6 & 8 \\
\hline PER MIL & 0.31 & 0.27 & 0.49 & 0.29 & 0.41 & 0.38 & 0.29 & 0.4 & 0.21 & 0.27 \\
\hline
\end{tabular}

The relevant examples, which are all found in 1830 s, are shown below: 
(48) a. Come forth, I say, " he continued, hammering away at the door with the butt of his whip, " or, by my beard! ay, by each particular hair of my beard, will I break down thy crazy door.

(1838, Burton; or The Sieges Volume 1)

b. ... If Water parted' is your tune, you may stick to Arne, but I'll give you a touch of Kotzwara - a specimen of the Battle of Prague,'with a little of the Halistone chorus."' Minim hammered away at the door; but not being able to beat in the panels with his feet,

(1838, Charcoal Sketches)

c. After the duet, a universal chorus of applause! And now arriettas and duettinos succeed each other, and right merrily I hammer away at the thousand-times-repeated accompaniment.

(1839, Hyperion)

\subsubsection{Chew $^{8}$}

Let us now consider the cases of the verb chew, a verb of ingesting, according to Levin (1993). The frequency of the occurrence of the phrasal verb chew away is shown below:

(49) The frequencies of the occurrence of the phrasal verb chew away

\begin{tabular}{lcccccccccc}
\hline SECTION & 1810 & 1820 & 1830 & 1840 & 1850 & 1860 & 1870 & 1880 & 1890 & 1900 \\
\hline FREQ & 0 & 0 & 0 & 0 & 0 & 0 & 0 & 1 & 2 & 1 \\
\hline PER MIL & 0 & 0 & 0 & 0 & 0 & 0 & 0 & 0.05 & 0.1 & 0.05 \\
\hline SECTION & 1910 & 1920 & 1930 & 1940 & 1950 & 1960 & 1970 & 1980 & 1990 & 2000 \\
\hline FREQ & 2 & 1 & 2 & 0 & 5 & 2 & 8 & 0 & 6 & 5 \\
\hline PER MIL & 0.09 & 0.04 & 0.08 & 0 & 0.2 & 0.07 & 0.34 & 0 & 0.21 & 0.17 \\
\hline
\end{tabular}

As shown in (49), the phrasal verb chew away appeared in 1880s. The following tables are the frequencies of the occurrence of the transitive and intransitive usage of chew away.

(50) The frequencies of the occurrence of the transitive chew away

\begin{tabular}{lcccccccccc}
\hline SECTION & 1810 & 1820 & 1830 & 1840 & 1850 & 1860 & 1870 & 1880 & 1890 & 1900 \\
\hline FREQ & 0 & 0 & 0 & 0 & 0 & 0 & 0 & 0 & 0 & 0 \\
\hline PER MIL & 0 & 0 & 0 & 0 & 0 & 0 & 0 & 0 & 0 & 0 \\
\hline SECTION & 1910 & 1920 & 1930 & 1940 & 1950 & 1960 & 1970 & 1980 & 1990 & 2000 \\
\hline FREQ & 2 & 0 & 1 & 0 & 2 & 1 & 0 & 0 & 4 & 3 \\
\hline PER MIL & 0.1 & 0 & 0.04 & 0 & 0.08 & 0.04 & 0 & 0 & 0.1 & 0.1 \\
\hline
\end{tabular}

(51) The frequencies of the occurrence of the intransitive chew away

\begin{tabular}{lcccccccccc}
\hline SECTION & 1810 & 1820 & 1830 & 1840 & 1850 & 1860 & 1870 & 1880 & 1890 & 1900 \\
\hline FREQ & 0 & 0 & 0 & 0 & 0 & 0 & 0 & 1 & 2 & 1 \\
\hline PER MIL & 0 & 0 & 0 & 0 & 0 & 0 & 0 & 0.05 & 0.1 & 0.05 \\
\hline SECTION & 1910 & 1920 & 1930 & 1940 & 1950 & 1960 & 1970 & 1980 & 1990 & 2000 \\
\hline FREQ & 0 & 1 & 1 & 0 & 3 & 1 & 8 & 0 & 2 & 2 \\
\hline PER MIL & 0 & 0.04 & 0.04 & 0 & 0.12 & 0.04 & 0.34 & 0 & 0.07 & 0.07 \\
\hline
\end{tabular}

Consider the cases where the intransitive usage of chew away is used. The following example appears in the conjunct clause, which indicates that the phrasal verb chew away may involve an unspecified object deletion.

(52) Howling Wolf also chewed away and cheered on his friend for, though he did not feel that Joe should still keep on dragging him along,

(1924, Bob Hunt in Canada)

Let us shift our attention to the frequencies of the occurrence of the phrasal verb chew away at, which is a typical instance of the continuative or iterative aspectual away: 
(53) The frequencies of the occurrence of chew away at

\begin{tabular}{lcccccccccc}
\hline SECTION & 1810 & 1820 & 1830 & 1840 & 1850 & 1860 & 1870 & 1880 & 1890 & 1900 \\
\hline FREQ & 0 & 0 & 0 & 0 & 0 & 0 & 0 & 1 & 0 & 0 \\
\hline PER MIL & 0 & 0 & 0 & 0 & 0 & 0 & 0 & 0.05 & 0 & 0 \\
\hline SECTION & 1910 & 1920 & 1930 & 1940 & 1950 & 1960 & 1970 & 1980 & 1990 & 2000 \\
\hline FREQ & 0 & 0 & 1 & 0 & 1 & 1 & 5 & 0 & 2 & 2 \\
\hline PER MIL & 0 & 0 & 0.04 & 0 & 0.04 & 0.04 & 0.21 & 0 & 0.07 & 0.07 \\
\hline
\end{tabular}

The example of the first appearance of chew away at is shown below:

(54) ... he stands the picture of pure animal enjoyment, chewing away at one end of the root,

(1887, Harpers)

In (54), the preposition at denotes the location of the event, which means that this usage is not an instance of the conative construction.

The next example, which appeared in 1930s, is given in (55). This is one of the clear instances of the conative construction with the continuative or iterative aspectual away.

(55) " the old man said as he chewed away at the remains of his stogy. "

(1932, Young Lonigan)

The following table shows that the frequencies of the occurrence of the conative chew away at. As is clear from (56), the conative construction with the continuative or iterative aspectual away is found in 1930s, which is the same period as the first appearance of the conative eat away at.

(56) The frequencies of the occurrence of conative chew away at

\begin{tabular}{lcccccccccc}
\hline SECTION & 1810 & 1820 & 1830 & 1840 & 1850 & 1860 & 1870 & 1880 & 1890 & 1900 \\
\hline FREQ & 0 & 0 & 0 & 0 & 0 & 0 & 0 & 0 & 0 & 0 \\
\hline PER MIL & 0 & 0 & 0 & 0 & 0 & 0 & 0 & 0 & 0 & 0 \\
\hline SECTION & 1910 & 1920 & 1930 & 1940 & 1950 & 1960 & 1970 & 1980 & 1990 & 2000 \\
\hline FREQ & 0 & 0 & 1 & 0 & 1 & 0 & 5 & 0 & 2 & 2 \\
\hline PER MIL & 0 & 0 & 0.04 & 0 & 0.04 & 0 & 0.21 & 0 & 0.07 & 0.07 \\
\hline
\end{tabular}

What is also remarkable in this phrasal verb chew away is that it seems that the phrasal verb was compatible with the preposition on, which is a type of the conative construction. Furthermore, these usages can be found in the late $19^{\text {th }}$ century, as shown in the following examples:

(57) a. She talked to Babcock in an unabashed, self-possessed way, pouring out the smoking coffee in the flask cup, chewing away on the pigs' feet, and throwing the bones to the goat, who sniffed them contemptously.

(1896, Tom Grogan)

b. ... he just sat hunched up on the arm of the old sofa, swinging one of his long legs, and scowling, and chewing away on a piece of straw he'd pulled out of the whisk-broom, ...

(1896, We Ten Or, The Story of the Roses)

c. Police Commissioner Bingham sat in his office at Headquarters yesterday chewing away on the stem of his old corn-cob pipe.

(1908, Asks \$100,000 to Stop Crime Factories)

(58) The frequencies of occurrences of the phrasal verb chew away on

\begin{tabular}{lcccccccccc}
\hline SECTION & 1810 & 1820 & 1830 & 1840 & 1850 & 1860 & 1870 & 1880 & 1890 & 1900 \\
\hline FREQ & 0 & 0 & 0 & 0 & 0 & 0 & 0 & 0 & 2 & 1 \\
\hline PER MIL & 0 & 0 & 0 & 0 & 0 & 0 & 0 & 0 & 0.1 & 0.05 \\
\hline SECTION & 1910 & 1920 & 1930 & 1940 & 1950 & 1960 & 1970 & 1980 & 1990 & 2000 \\
\hline FREQ & 0 & 0 & 0 & 0 & 0 & 0 & 1 & 0 & 0 & 0 \\
\hline PER MIL & 0 & 0 & 0 & 0 & 0 & 0 & 0.04 & 0 & 0 & 0 \\
\hline
\end{tabular}


These examples indicate that the verb chew was compatible with the continuative or iterative aspectual away in the late $19^{\text {th }}$ century.

\subsubsection{Gnaw and Nibble}

The verbs such as gnaw and nibble are also compatible with the continuative or iterative aspectual away, according to Shimada (1985). Since these verbs are also categorized as verbs of ingestion (Levin (1993)), it is worth considering when these verbs can be connected with the continuative or iterative aspectual away. Let us consider the frequencies of occurrences of the phrasal verbs gnaw away, gnaw away at, nibble away, and nibble away at:

(59) The frequencies of occurrences of the phrasal verb gnaw away

\begin{tabular}{lcccccccccc}
\hline SECTION & 1810 & 1820 & 1830 & 1840 & 1850 & 1860 & 1870 & 1880 & 1890 & 1900 \\
\hline FREQ & 0 & 1 & 0 & 1 & 2 & 3 & 4 & 6 & 1 & 2 \\
\hline PER MIL & 0 & 0.14 & 0 & 0.06 & 0.12 & 0.18 & 0.22 & 0.3 & 0.05 & 0.09 \\
\hline SECTION & 1910 & 1920 & 1930 & 1940 & 1950 & 1960 & 1970 & 1980 & 1990 & 2000 \\
\hline FREQ & 0 & 3 & 2 & 4 & 6 & 5 & 6 & 4 & 5 & 6 \\
\hline PER MIL & 0 & 0.12 & 0.08 & 0.16 & 0.24 & 0.21 & 0.25 & 0.16 & 0.18 & 0.2 \\
\hline
\end{tabular}

(60) The frequencies of occurrences of the phrasal verb gnaw away at

\begin{tabular}{lcccccccccc}
\hline SECTION & 1810 & 1820 & 1830 & 1840 & 1850 & 1860 & 1870 & 1880 & 1890 & 1900 \\
\hline FREQ & 0 & 0 & 0 & 0 & 2 & 0 & 0 & 2 & 0 & 0 \\
\hline PER MIL & 0 & 0 & 0 & 0 & 0.12 & 0 & 0 & 0.1 & 0 & 0 \\
\hline SECTION & 1910 & 1920 & 1930 & 1940 & 1950 & 1960 & 1970 & 1980 & 1990 & 2000 \\
\hline FREQ & 0 & 1 & 0 & 1 & 1 & 4 & 4 & 2 & 0 & 3 \\
\hline PER MIL & 0 & 0.04 & 0 & 0.04 & 0.04 & 0.17 & 0.17 & 0.08 & 0 & 0.1 \\
\hline
\end{tabular}

(61) The frequencies of occurrences of the phrasal verb nibble away

\begin{tabular}{lcccccccccc}
\hline SECTION & 1810 & 1820 & 1830 & 1840 & 1850 & 1860 & 1870 & 1880 & 1890 & 1900 \\
\hline FREQ & 0 & 0 & 1 & 0 & 4 & 2 & 2 & 0 & 0 & 0 \\
\hline PER MIL & 0 & 0 & 0.07 & 0 & 0.24 & 0.12 & 0.11 & 0 & 0 & 0 \\
\hline SECTION & 1910 & 1920 & 1930 & 1940 & 1950 & 1960 & 1970 & 1980 & 1990 & 2000 \\
\hline FREQ & 1 & 2 & 0 & 2 & 7 & 10 & 6 & 12 & 7 & 5 \\
\hline PER MIL & 0.04 & 0.08 & 0 & 0.08 & 0.29 & 0.42 & 0.25 & 0.47 & 0.25 & 0.17 \\
\hline
\end{tabular}

(62) The frequencies of occurrences of the phrasal verb nibble away at

\begin{tabular}{lcccccccccc}
\hline SECTION & 1810 & 1820 & 1830 & 1840 & 1850 & 1860 & 1870 & 1880 & 1890 & 1900 \\
\hline FREQ & 0 & 0 & 0 & 0 & 1 & 1 & 1 & 0 & 0 & 0 \\
\hline PER MIL & 0 & 0 & 0 & 0 & 0.06 & 0.06 & 0.05 & 0 & 0 & 0 \\
\hline SECTION & 1910 & 1920 & 1930 & 1940 & 1950 & 1960 & 1970 & 1980 & 1990 & 2000 \\
\hline FREQ & 1 & 1 & 0 & 0 & 4 & 5 & 4 & 8 & 6 & 3 \\
\hline PER MIL & 0.04 & 0.04 & 0 & 0 & 0.16 & 0.21 & 0.17 & 0.32 & 0.21 & 0.1 \\
\hline
\end{tabular}

As indicated in (60) and (62), the phrasal verbs gnaw away and nibble away seem to be compatible with the preposition at to form a conative construction. The following examples in (63) and (64) indicate that the continuative or iterative aspectual away may be used in 1850s.

(63) a. "The two men saunter out together, pass up a narrow lane leading from King Street, and are soon groping their way up the dark stairway of an old, neglected-looking wooden building, that for several years has remained deserted by everything but rats and politicians, one seeming to gnaw away at the bowels of the nation, the other at the bowels of the old building.

(1856, Justice in the By-Ways, a Tale of Life)

b. That return is the day dream of her heart; in it she sees her future brightening. Such are the cherished thoughts of a pure mind. Poverty may gnaw away at the hearthstone, cares and sorrow may fall thick in 
your path, ...

(64) a. I have no idea that he really lacked sustenance; but it was quite touching, nevertheless, to hear him nibbling away at our crusts.

(1852, The Blithedale Romance)

b. "Just as you say, Rufus," returned his mother meekly, nibbling away at the bacon on her plate and feeling vastly uncomfortable.

(1919, In Apple-Blossom Time A Fairy-Tale to Date)

Thus, the examples above show that like chew, the verbs gnaw and nibble has been compatible with the continuative or iterative aspectual away since the middle of the $19^{\text {th }}$ century.

\subsection{Accomplishment verbs}

\subsubsection{Eat}

Let us first consider the verb eat, a typical verb of ingesting. The following tables show the total frequencies of the occurrence of the phrasal verb eat away, and the frequencies of the occurrence of its transitive and intransitive usages, respectively.

(65) The frequency of the occurrence of the phrasal verb eat away

\begin{tabular}{lcccccccccc}
\hline SECTION & 1810 & 1820 & 1830 & 1840 & 1850 & 1860 & 1870 & 1880 & 1890 & 1900 \\
\hline FREQ & 0 & 1 & 8 & 4 & 4 & 9 & 13 & 8 & 12 & 15 \\
\hline PER MIL & 0 & 0.14 & 0.58 & 0.25 & 0.24 & 0.53 & 0.7 & 0.39 & 0.58 & 0.68 \\
\hline SECTION & 1910 & 1920 & 1930 & 1940 & 1950 & 1960 & 1970 & 1980 & 1990 & 2000 \\
\hline FREQ & 8 & 9 & 17 & 21 & 27 & 29 & 24 & 34 & 49 & 63 \\
\hline PER MIL & 0.35 & 0.35 & 0.73 & 0.86 & 1.1 & 1.25 & 1.01 & 1.34 & 1.75 & 2.13 \\
\hline
\end{tabular}

(66) The frequency of the occurrence of the transitive eat away NP

\begin{tabular}{lcccccccccc}
\hline SECTION & 1810 & 1820 & 1830 & 1840 & 1850 & 1860 & 1870 & 1880 & 1890 & 1900 \\
\hline FREQ & 0 & 1 & 3 & 3 & 2 & 9 & 11 & 7 & 11 & 13 \\
\hline PER MIL & 0 & 0.14 & 0.07 & 0.18 & 0.12 & 0.53 & 0.54 & 0.34 & 0.58 & 0.54 \\
\hline SECTION & 1910 & 1920 & 1930 & 1940 & 1950 & 1960 & 1970 & 1980 & 1990 & 2000 \\
\hline FREQ & 19 & 9 & 13 & 18 & 19 & 21 & 16 & 14 & 26 & 28 \\
\hline PER MIL & 0.31 & 0.35 & 0.48 & 0.82 & 0.73 & 0.79 & 0.67 & 0.47 & 0.93 & 0.95 \\
\hline
\end{tabular}

(67) The frequency of the occurrence of the intransitive eat away

\begin{tabular}{lcccccccccc}
\hline SECTION & 1810 & 1820 & 1830 & 1840 & 1850 & 1860 & 1870 & 1880 & 1890 & 1900 \\
\hline FREQ & 0 & 0 & 5 & 1 & 2 & 0 & 2 & 1 & 1 & 2 \\
\hline PER MIL & 0 & 0 & 0.5 & 0.06 & 0.12 & 0 & 0.16 & 0.05 & 0 & 0.14 \\
\hline SECTION & 1910 & 1920 & 1930 & 1940 & 1950 & 1960 & 1970 & 1980 & 1990 & 2000 \\
\hline FREQ & 0 & 0 & 4 & 3 & 8 & 8 & 8 & 2 & 23 & 35 \\
\hline PER MIL & 0.04 & 0 & 0.2 & 0.04 & 0.28 & 0.42 & 0.34 & 0.87 & 0.82 & 1.18 \\
\hline
\end{tabular}

It seems that transitive usage of the particle verb eat away has developed earlier than intransitive usage. However, as pointed out by an anonymous reviewer, the intransitive usage of eat away is also found in the $19^{\text {th }}$ century, which does not appear to support our analysis that the continuative or iterative aspectual away has developed from the directional away. In order to examine how the intransitive usage of the phrasal verb eat away is used in a context, let us consider the following tables: 
(68) The frequency of the occurrence of the intransitive eat away in conjuncts and in the imperative form

\begin{tabular}{lcccccccccc}
\hline SECTION & 1810 & 1820 & 1830 & 1840 & 1850 & 1860 & 1870 & 1880 & 1890 & 1900 \\
\hline FREQ & 0 & 0 & 7 & 1 & 2 & 0 & 3 & 1 & 0 & 3 \\
\hline PER MIL & 0 & 0 & 0.5 & 0.06 & 0.12 & 0 & 0.16 & 0.05 & 0 & 0.14 \\
\hline SECTION & 1910 & 1920 & 1930 & 1940 & 1950 & 1960 & 1970 & 1980 & 1990 & 2000 \\
\hline FREQ & 1 & 0 & 1 & 0 & 0 & 1 & 0 & 2 & 0 & 0 \\
\hline PER MIL & 0.04 & 0 & 0.04 & 0 & 0 & 0.04 & 0 & 0.08 & 0 & 0 \\
\hline
\end{tabular}

(69) The frequency of the occurrence of eat away at

\begin{tabular}{lcccccccccc}
\hline SECTION & 1810 & 1820 & 1830 & 1840 & 1850 & 1860 & 1870 & 1880 & 1890 & 1900 \\
\hline FREQ & 0 & 0 & 0 & 0 & 0 & 0 & 0 & 0 & 0 & 0 \\
\hline PER MIL & 0 & 0 & 0 & 0 & 0 & 0 & 0 & 0 & 0 & 0 \\
\hline SECTION & 1910 & 1920 & 1930 & 1940 & 1950 & 1960 & 1970 & 1980 & 1990 & 2000 \\
\hline FREQ & 0 & 0 & 2 & 2 & 8 & 8 & 7 & 18 & 22 & 35 \\
\hline PER MIL & 0 & 0 & 0.08 & 0.08 & 0.33 & 0.33 & 0.29 & 0.71 & 0.79 & 1.18 \\
\hline
\end{tabular}

Interestingly, the form eat away at began to be used in 1930s, and it has been increasing since then. On the other hand, the intransitive usage of the phrasal verb eat away was mainly found in the imperative form or in the conjunct clause before that period. ${ }^{10}$ The relevant examples are shown below:

(70) a. ... jest after you come abroad - eat away man! Eat away!

b. Not a I'vienny in the till. Eat away! Hell-born boy!

(1833, Down Easters Volume 1)

c. Mr. Hodge ate away and said nothing.

(1833, By Order King)

d. It ate away from beneath; the sun ate from above.

(1871, Dukesborough Tales)

(1903, The Cull of the Wild)

(71) a. ... that they have eaten away not only at the pictures of God given by the theologians but at the portraits of man as drawn by the humanists.

b. ... He looked very grim and bitter, eating away at his creamedicken.

(1930, Harpers Magazine)

c. "I can imagine how ambition eats away at you."

(1931, Money From Home)

(1952, Harpers Magazine)

d. To say that the worker is losing his courage because the communist ulcer is eating away at him, is after all just too stupid.

(1968, George Braziller, New York)

The data (71) indicate that the particle away started to concatenate with the verb eat in 1930s, which is much later than activity verbs discussed in the previous subsection.

\subsubsection{Wash $^{11}$}

Let us next consider the verb wash. The following tables are the total frequency of the occurrence of the phrasal verb wash away, and the frequencies of its transitive and intransitive usages, respectively.

(72) Total frequencies of the occurrence of the phrasal verb wash away

\begin{tabular}{lcccccccccc}
\hline SECTION & 1810 & 1820 & 1830 & 1840 & 1850 & 1860 & 1870 & 1880 & 1890 & 1900 \\
\hline FREQ & 7 & 11 & 37 & 51 & 40 & 43 & 46 & 53 & 53 & 43 \\
\hline PER MIL & 5.93 & 1.59 & 2.69 & 3.18 & 2.43 & 2.52 & 2.48 & 2.61 & 2.57 & 1.95 \\
\hline SECTION & 1910 & 1920 & 1930 & 1940 & 1950 & 1960 & 1970 & 1980 & 1990 & 2000 \\
\hline FREQ & 36 & 47 & 50 & 61 & 60 & 55 & 74 & 73 & 84 & 95 \\
\hline PER MIL & 1.59 & 1.83 & 2.03 & 2.51 & 2.44 & 2.29 & 3.11 & 2.88 & 3.01 & 3.21 \\
\hline
\end{tabular}


(73) The frequency of the occurrence of the transitive wash away NP

\begin{tabular}{lcccccccccc}
\hline SECTION & 1810 & 1820 & 1830 & 1840 & 1850 & 1860 & 1870 & 1880 & 1890 & 1900 \\
\hline FREQ & 6 & 10 & 37 & 47 & 36 & 42 & 43 & 49 & 50 & 38 \\
\hline PER MIL & 5.08 & 1.44 & 2.69 & 2.93 & 2.19 & 2.46 & 2.32 & 2.41 & 2.43 & 1.72 \\
\hline SECTION & 1910 & 1920 & 1930 & 1940 & 1950 & 1960 & 1970 & 1980 & 1990 & 2000 \\
\hline FREQ & 34 & 42 & 44 & 56 & 49 & 43 & 61 & 58 & 69 & 74 \\
\hline PER MIL & 1.49 & 1.64 & 1.79 & 2.3 & 2 & 1.79 & 2.56 & 2.29 & 2.47 & 2.5 \\
\hline
\end{tabular}

(74) The frequencies of the occurrence of the intransitive wash away

\begin{tabular}{lcccccccccc}
\hline SECTION & 1810 & 1820 & 1830 & 1840 & 1850 & 1860 & 1870 & 1880 & 1890 & 1900 \\
\hline FREQ & 1 & 1 & 0 & 4 & 4 & 1 & 3 & 4 & 3 & 5 \\
\hline PER MIL & 0.85 & 0.15 & 0 & 0.25 & 0.24 & 0.06 & 0.16 & 0.2 & 0.14 & 0.23 \\
\hline SECTION & 1910 & 1920 & 1930 & 1940 & 1950 & 1960 & 1970 & 1980 & 1990 & 2000 \\
\hline FREQ & 2 & 5 & 6 & 5 & 11 & 8 & 13 & 15 & 15 & 21 \\
\hline PER MIL & 0.1 & 0.19 & 0.24 & 0.21 & 0.44 & 0.5 & 0.55 & 0.57 & 0.54 & 0.71 \\
\hline
\end{tabular}

Let us consider in more detail the cases where the intransitive usage of wash away is used. The particle verb in (75a) and (75b) is in the imperative form, and in the conjunct clause, respectively. The particle away in (75c) and (75d) seem to be interpreted as the directional meaning or the completive aspect.

(75) a. Lord Conrad That guilty spot, hath blood's unblenching stain Too deeply blazon'd in its hue of crime, For tears to wash away!

(1818, The Corsair)

b. It is true the three rocks are precisely those which would most readily admit of such *n effect, the slate crumbling, the limestone then falling by its weight, and the sandstone disintegrating and washing away.

(1822, North American Review)

c. "Well, no, I don't jist ezactly mind - (remember) - but I a sorter allow maybe prehaps two's for the Snake Run Sittlemint's folk's" - (washing away as if the article was very hard to get clean).

(1843, The New Purchase)

d. Daily have I resorted to this spot, And wrote Alphonso in the yellow sand, Which, when the rising tide would wash away, I turn'd to read it printed in my breast, ...

(1844, Merlin)

In order to investigate the clear instance of the continuative or iterative aspectual away, consider the following table, which indicates that the particle verb wash away occurs with the preposition at.

(76) The frequencies of occurrence of wash away at

\begin{tabular}{lcccccccccc}
\hline SECTION & 1810 & 1820 & 1830 & 1840 & 1850 & 1860 & 1870 & 1880 & 1890 & 1900 \\
\hline FREQ & 1 & 1 & 0 & 4 & 4 & 1 & 3 & 4 & 3 & 5 \\
\hline PER MIL & 0.85 & 0.15 & 0 & 0.25 & 0.24 & 0.06 & 0.16 & 0.2 & 0.14 & 0.23 \\
\hline SECTION & 1910 & 1920 & 1930 & 1940 & 1950 & 1960 & 1970 & 1980 & 1990 & 2000 \\
\hline FREQ & 2 & 5 & 6 & 5 & 11 & 8 & 13 & 15 & 15 & 21 \\
\hline PER MIL & 0.1 & 0.19 & 0.24 & 0.21 & 0.44 & 0.5 & 0.55 & 0.57 & 0.54 & 0.71 \\
\hline
\end{tabular}

The following examples are all instances containing the verb sequence wash away at:

(77) a. I will go forth and stand in a summer shower, and all the worldly dust that has collected on me shall be washed away at once, and my heart will be like a bank of fresh flowers for the weary to rest upon.

(1887, Howthorne)

b. ... the Evanston shore, including the Northwestern university campus, is washing away at a rate that will require elaborate systems of protect.

(1946, Chicago Tribune)

c. The fact is that the detente policy is washing away at the foundations of the alliance and is testing them.

(1974, Christian Science Monitor) 
d. Those fields that now are offering up such bounty are so intensively farmed, in their owners' mad race against high costs, that the topsoil is washing away at an alarming rate.

(1981, Time Magazine)

The preposition at following the particle away in (77a), (77b), and (77d) does not seem to be connected with the particle verb wash away, because of the idiomatic expressions such as at once, or at a rate. The only instance we can witness is (77c), where the verb sequence washing away at functions as a particle verb with the conative construction. ${ }^{12}$ Even though the number of the occurrence of wash away at is very small, the clear instance of the continuative or iterative aspectual away in (77c) indicates that it is concatenated with the verb wash in 1970s, which is later than the first appearance of the phrasal verb eat away at.

\subsubsection{Burn}

Let us finally consider the verb burn. The following tables indicate the frequencies of the occurrence of the transitive and intransitive usage of the particle verb burn away, respectively.

(78) The frequency of the occurrence of the phrasal verb burn away

\begin{tabular}{lcccccccccc}
\hline SECTION & 1810 & 1820 & 1830 & 1840 & 1850 & 1860 & 1870 & 1880 & 1890 & 1900 \\
\hline FREQ & 0 & 2 & 5 & 6 & 6 & 8 & 9 & 12 & 12 & 15 \\
\hline PER MIL & 0 & 0.29 & 0.36 & 0.37 & 0.36 & 0.47 & 0.48 & 0.59 & 0.58 & 0.68 \\
\hline SECTION & 1910 & 1920 & 1930 & 1940 & 1950 & 1960 & 1970 & 1980 & 1990 & 2000 \\
\hline FREQ & 11 & 12 & 11 & 18 & 19 & 24 & 19 & 29 & 28 & 39 \\
\hline PER MIL & 0.48 & 0.47 & 0.45 & 0.74 & 0.77 & 1 & 0.8 & 1.15 & 1 & 1.32 \\
\hline
\end{tabular}

(79) The frequency of the occurrence of the transitive burn away NP

\begin{tabular}{lcccccccccc}
\hline SECTION & 1810 & 1820 & 1830 & 1840 & 1850 & 1860 & 1870 & 1880 & 1890 & 1900 \\
\hline FREQ & 0 & 1 & 4 & 5 & 3 & 7 & 6 & 8 & 7 & 9 \\
\hline PER MIL & 0 & 0.14 & 0.29 & 0.31 & 0.18 & 0.41 & 0.32 & 0.39 & 0.34 & 0.41 \\
\hline SECTION & 1910 & 1920 & 1930 & 1940 & 1950 & 1960 & 1970 & 1980 & 1990 & 2000 \\
\hline FREQ & 9 & 9 & 8 & 10 & 10 & 13 & 14 & 19 & 19 & 28 \\
\hline PER MIL & 0.4 & 0.35 & 0.32 & 0.41 & 0.41 & 0.55 & 0.59 & 0.75 & 0.68 & 0.95 \\
\hline
\end{tabular}

(80) The frequency of the occurrence of the intransitive burn away

\begin{tabular}{lcccccccccc}
\hline SECTION & 1810 & 1820 & 1830 & 1840 & 1850 & 1860 & 1870 & 1880 & 1890 & 1900 \\
\hline FREQ & 0 & 1 & 1 & 1 & 3 & 1 & 3 & 4 & 5 & 6 \\
\hline PER MIL & 0 & 0.14 & 0.07 & 0.06 & 0.18 & 0.06 & 0.16 & 0.2 & 0.24 & 0.27 \\
\hline SECTION & 1910 & 1920 & 1930 & 1940 & 1950 & 1960 & 1970 & 1980 & 1990 & 2000 \\
\hline FREQ & 2 & 3 & 3 & 8 & 9 & 11 & 5 & 10 & 7 & 11 \\
\hline PER MIL & 0.08 & 0.12 & 0.13 & 0.33 & 0.37 & 0.45 & 0.21 & 0.4 & 0.32 & 0.37 \\
\hline
\end{tabular}

Let us now check in more detail the instances where the intransitive usage of burn away is used. In (81a), (81b) and (81c), burn away appears in the conjunct clause, which can be regarded as an instance of the unspecified object deletion. The usage in (81d) seems problematic but it can also be interpreted as a directional or completive meaning.

(81) a. And wilt thou go, and leave thy blighting scorn To dry the fountains of my heart, and turn The kindness of my desperate passion To the dark and bitter throb of utter agony? And wilt thou go, and leave me here, to burn Away with no companion but Despair;

(1822, Odofriede; the Outcast)

b. "It is very true," said the neophyte, "the mountains burn away, the sea wastes itself into air, but the soul that God has given us consumes not.

(1834, Calavar)

c. I was greatly surprised at finding the window closed tightly, and a suffocating smell of charcoal in the room. There was a furnace in the corner; but the coal had burned away to embers. I was alarmed, but knew not the terrible meaning what I saw!

(1849, Kate the Accomplice) 
d. But for my aid, his life would have burned away in torments, within the first two years after the perpetration of his crime and thine.

(1850, The Scarlet Letter)

The following table indicates the frequency of the occurrence of burn away at, a clear instance containing the continuative or iterative aspectual away. All usages of the particle verb are given in (83):

(82) The frequency of the occurrence of burn away at

\begin{tabular}{lcccccccccc}
\hline SECTION & 1810 & 1820 & 1830 & 1840 & 1850 & 1860 & 1870 & 1880 & 1890 & 1900 \\
\hline FREQ & 0 & 0 & 0 & 0 & 0 & 0 & 0 & 1 & 0 & 0 \\
\hline PER MIL & 0 & 0 & 0 & 0 & 0 & 0 & 0 & 0.05 & 0 & 0 \\
\hline SECTION & 1910 & 1920 & 1930 & 1940 & 1950 & 1960 & 1970 & 1980 & 1990 & 2000 \\
\hline FREQ & 0 & 0 & 0 & 0 & 1 & 0 & 1 & 0 & 0 & 0 \\
\hline PER MIL & 0 & 0 & 0 & 0 & 0.04 & 0 & 0.04 & 0 & 0 & 0 \\
\hline
\end{tabular}

(83) a. When I reached the pilot-house and looked down on the hatchway, I saw, not only smoke coming up, but every now and then a tongue of flame. The hatch was burning away at the edges.

(1880, A Jolly Fellowship)

b. The titan looked up at the welllightedrooms of the square old house and then took in the activity at the stables. "Horses eating their heads off, "he muttered. "Candles burning away at a ruinous rate. How does she manage it, Jonathan?"

(1955, Something of Value)

c. "No, I suspect it is simply leaving the main sequence and' appens to be going t'rough a brief green phase. " Hydrogen burned away at the core, the nuclear reactions moving outward - "Wait. Doesn't it become a red giant?"

(1978, Whistle)

The usages of the preposition at in (83a) and (83b) is connected with the nouns that follows it, such as at the edge, or at a rate, so that the verb sequence burn away at in these examples cannot be regarded as a conative construction. The clearest instance of phrasal verb burn away at with the conative construction is (83c), which is collected in 1970's. Thus, we may conclude that the continuative or iterative aspectual away has developed quite recently even though the frequency of the particle verb burn away at is very small. ${ }^{13}$

\subsection{Discussion}

To summarize so far, we have shown that the appearance of the continuative or iterative aspectual away is dependent upon the verbs; the activity verbs such as puff, hammer, chew, gnaw, and nibble began to be concatenated with the continuative or iterative aspectual away in the $19^{\text {th }}$ century, the verb eat, in 1930s, the verbs wash and burn, in 1970s. Even though the number of the occurrence of the continuative or iterative aspectual away is so small, it is worth considering why this is so. In the reminder of this section, I will just speculate the reason for this.

The crucial difference between the verb eat, wash, and burn, on the one hand, and chew, gnaw and nibble, on the other, is whether these verbs can take an incremental theme object. It has been reported in the literature that the verb eat takes incremental theme object, as shown below:

(84) a. He ate three pieces of wedding cake in/??for an hour. (quantized object: telic)

b. He ate wedding cake for/??in an hour. (non-quantized object: atelic)

The verbs of consumption such as eat and the verbs of destruction such as burn are typical example of incremental theme verbs (cf. Krifka (1986, 1992), and Dowty (1987)). Furthermore, Crãiniceanu and Baciu (2009) points out that the verb wash also takes an incremental theme object, as shown in (85):

(85) John washed three windows

a. ... (clean) in an hour

b. ... for an hour, but none of them got completely clean

On the other hand, chew, gnaw and nibble cannot take an incremental theme object, so that the durative adverbial is compatible with them because the object is not the incremental theme, as shown in (86):

(86) a. The cowboy chewed two pieces of beef jerkey for/??in an hour. (Bruening (2010)) 
b. The boy gnawed the chicken for/??in an hour.

c. The child nibbled the cookie for/??in an hour.

(Bruening (2010))

Recall that the verbs such as eat can do not have to take the direct object that can be recovered from the discourse, which means that the recovered object should be definite. Therefore, the whole event would be telic, irrelevant of the realization of the direct object. This makes us hypothesize that there is a shift from telicity to atelicity, and that the atelicity of the sentences with unspecified object deletion has developed later. If this is the case, it would take some time for the verb eat to combine with the continuative or iterative aspectual away.

Let us next consider the conative construction. As is well-known, the verb eat allows the conative construction. If so, then it is mysterious why the verb sequence eat away at appears later than hammer away at, a verb that also allows the conative construction. As the following table reveals, the verb sequence eat at has developed in the $20^{\text {th }}$ century. The relevant examples found in COHA are shown in (88):

(87) The frequency of the occurrence of eat at with conative construction

\begin{tabular}{lcccccccccc}
\hline SECTION & 1810 & 1820 & 1830 & 1840 & 1850 & 1860 & 1870 & 1880 & 1890 & 1900 \\
\hline FREQ & 0 & 0 & 0 & 0 & 0 & 0 & 0 & 0 & 0 & 0 \\
\hline PER MIL & 0 & 0 & 0 & 0 & 0 & 0 & 0 & 0 & 0 & 0 \\
\hline SECTION & 1910 & 1920 & 1930 & 1940 & 1950 & 1960 & 1970 & 1980 & 1990 & 2000 \\
\hline FREQ & 4 & 2 & 2 & 2 & 11 & 16 & 25 & 27 & 23 & 27 \\
\hline PER MIL & 0.18 & 0.08 & 0.08 & 0.08 & 0.45 & 0.67 & 1.05 & 1.07 & 0.82 & 0.98 \\
\hline
\end{tabular}

(88) a. How shall these things grow better, while you hold the garden of Italy - while the Greeks of the south and the Samnites and the men of the soil gather behind you on one side, and the Gauls and Etruscans muster in the north? The water is eating at the mole; soon the waves will lash up and sweep it from its foundations.

(1901, The Lion's Brood)

b. But Harvey said that blood was thicker than water with him, and no cousin o' his could come to Goshen and go away without eatin' a meal at his house. So it was fixed up that everybody else was to eat at the barbecue, and Harvey was to take Judge McGowan over to his house to a family dinner-party.

(1907, Aunt Jane of Kentucky)

We could find several instances of the sequence eat at in the $19^{\text {th }}$ century, but all the examples in (89) contain the preposition at which functions as a locative expression.

(89) a. I will take you for my friend, and because you are my friend, I will eat at your table;

(1823, The Wilderness; or, Braddock's Times)

b. "The housemaid now entered, and announced that Miss Rosa (a three-year old girl) had been throwing up the custard, and pie, and raisins, and so on, that she ate at dinner."

(1836, The Poor Rich Man and the Rich Poor Man)

Hence, it can be concluded that the phrasal verb eat away at has developed later than other phrasal verbs such as puff away at or hammer away at, because of the unavailability of the conative construction in the $19^{\text {th }}$ century.

In addition, the verbs such as wash and burn are incompatible with the conative construction at all, as shown in (90) and (91). Therefore, in order to generate wash away at or burn away at, the continuative or iterative aspectual away had to establish an independent status. After that, the phrasal verbs could combine with the preposition at to form the conative construction. In this sense, one more step has to be needed to form the phrasal verb wash away at or burn away at, because the verbs themselves do not appear in the conative construction.

(90) a. John washed his face.

b. *John washed at his face.

(91) a. John burned the wood.

b. *John burned at the wood.

To conclude, the continuative or iterative aspectual away has developed in the $19^{\text {th }}$ century, and the interaction of the particle away and the properties of the verbs affect the first appearance of the continuative or iterative aspectual away in the phrasal verbs. Therefore, the appearance of the continuative or iterative aspectual away totally depends on the properties of verbs, which is quite natural when we realize that it is not always the case that a particle can appear with any verb. 


\subsection{Summary}

From the observations discussed in the previous subsections, we can safely conclude the following two points, which is exactly what we have predicted in (36):

$(92)=(36)$ a. The continuative or iterative away appears with the intransitive or transitive activity verbs earlier than with the accomplishment verbs.

b. The transitive verbs which allow the conative construction occurs with the continuative or iterative away earlier than the transitive verbs which do not.

The corpus data constitutes a piece of evidence for the proposed analysis concerning the historical development of the particle away.

\section{Summary and Implications}

In this paper, I have investigated the historical development of the particle away from the syntactic point of view. Based on the distinction between the directional away and the continuative or iterative aspectual away (cf. Jackendoff (1997)), I have proposed that the directional away functions like the secondary resultative predicates, so that it is located in Res in the sense of Ramchand (2008). I have also argued, following Ishizaki (2012a, b), that the aspectual away can be divided into two: the completive away and the continuative or iterative away. The completive aspectual away is located in Asp, which is located just above ProcP with a slight modification of Ramchand's (2008) threelayered VP structure. On the other hand, the continuative or iterative away is realized in an Asp position, which is between AspP(completive) and InitP. This structural difference between the three usages of the particle away can be regarded as a grammaticalization process, and it is compatible with upward reanalysis proposed by Roberts and Roussou (2003). In addition, I have proposed that the aspectual shift from telic (the completive aspectual away) to atelic (continuative or iterative aspectual away) can be the result of grammaticalization; completive aspectual away focuses on the result state, but the continuative or iterative away focuses on the activity. The corpus data examined in Section 5 constitutes a piece of evidence for our claim.

Interestingly enough, the proposed historical development from Res to Asp can be reported in several languages. Investigating the historical development of V2 kiru 'cut' within the complex predicates in Japanese, Aoki (2010) argues that in Old Japanese, V2 kiru only had a literal meaning, i.e., it functioned as a main verb. In Middle Japanese, V2 kiru gained the completive aspectual meaning, but the V2 was only compatible with the change-of-state verbs. Furthermore, according to Aoki (2010), in Modern Japanese, V2 kiru with the aspectual meaning can concatenate with activity verbs, which does not imply the result state (such as tukai-kiru 'use-complete' or hasiri-kiru 'run-complete').

Aoki's (2010) findings are very important, if we consider it from the current analysis of complex V-V compounds in Japanese. Since Kageyama's (1993) seminal work on complex V-V compounds in Japanese, it has been assumed that there are two types of V-V compounds in Japanese: syntactic V-V compounds, and lexical V-V compounds. However, recent analysis of $\mathrm{V}-\mathrm{V}$ compounds in Japanese poses a question about the classification of $\mathrm{V}-\mathrm{V}$ compounds in Japanese and suggests that there is an additional type of V-V compounds in Japanese: namely that V2 as an aspectual head (cf. Nishiyama and Ogawa (this volume), Ogawa and Niinuma (2011), Fukuda (2012) and Kageyama (2012)). They argue that the aspectual V2 head is concatenated with VP whose head is V1, as shown in (93):

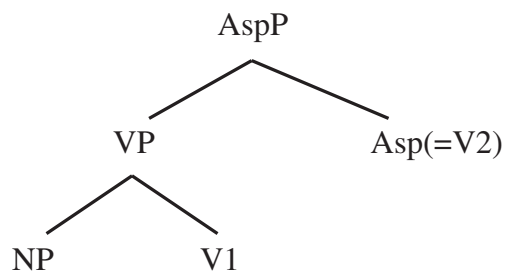

As for the lexical V-V compounds, it has been assumed in the literature that V1 and V2 are concatenated and V2 functions as a main verb (cf. Kageyama (1993), Nishiyama and Ogawa (this volume)). If so, we can say that V2 is grammaticalized so that it is realized in the Asp head, which is in conformity with the upward reanalysis (Roberts and Roussou (2003)).

Furthermore, Tasnim (2013) argues that V2 in Bengali also grammaticalized into an aspectual head. According to Tasnim (2013), the emergence of the aspectual meaning was about the $15^{\text {th }}$ century. This analysis can be extended to Bengali V-V compounds as well.

As is often noted in the literature, particles in Dutch also underwent the grammaticalization process (cf. Booij (2002), McIntyre (2004), and Los et al. (2012)), and the continuative aspectual particle door has developed from the preposition door, as in (94). 
(94) dat Jan [PP het hele jaar door] gewerkt heeft that John the whole year through worked has 'that John has worked all year round'

One of the plausible historical sources of the continuative aspectual particle, Los et al. (2012) provide, is shown in (95):

(95) Ende si beeden al den nacht dore in der vergaderinghen and they prayed all the night through in the assemblies 'And they prayed all night long in the assemblies' (1360, Bijbelvertaling)

Los et al. (2012) argue that the adverbial PP al den nacht dore 'all the night through' expressing the duration of the activity has been reanalyzed so that the adverbial NP al den nacht 'all the night' denotes the duration of the activity denoted by the phrasal verb dore-beeden 'lit. through-pray.'

If this is the case, we can say that English, Dutch, Japanese and Bengali underwent the similar grammaticalization process. The only differences are 1) the elements that underwent the grammaticalization process: verb or particle, and 2) the timing of the grammaticalization. The grammaticalization in Dutch, Japanese and Bengali has occurred earlier but English is just in the beginning of the grammaticalization, as suggested by the corpus data, as discussed in Section 5 .

A remaining question regarding the particle away is the status of so-called "time"-away construction, which seems to take an internal argument (cf. Jackendoff $(1997 \mathrm{a}, \mathrm{b})$ ). Thus, it poses a serious challenge for our analysis of aspectual away, which does not require any internal argument.

(96) a. Bill slept the afternoon away.

b. We're twistin' the night away.

Cappelle (2005) argues that there are two pieces of evidence against the view that the particle in this construction is aspectual. First, the particle in "time"-away construction can be modified, whereas the continuative or iterative aspectual away cannot.

(97) a. *Sally waltzed \{entirely/partly/half $\}$ away.

b. Sally waltzed the afternoon $\{$ entirely/partly/half $\}$ away

(Jackendoff 1997b: 540)

Second, as Jackendoff (1997a) points out, the "time"-away construction can undergo passivization:

(98) The evening had been nearly slept away, when I suddenly awoke with a start.

(Jackendoff (1997a: 82))

Therefore, Cappelle (2005) concludes that the "time"-away construction is different from the continuative or iterative aspectual away.

Interestingly, one of the anonymous reviewers points out that these arguments are not convincing enough. As for the ungrammaticality of the sentence (97a), we can say that it is simply ill-formed because these adverbs are semantically incompatible with the continuative or iterative meaning. The acceptable sentence (98) is not problematic at all. In the case of the continuative or iterative away, they are compatible with intransitive verbs, and thus the intransitive $\mathrm{V}+$ away construction cannot be passivized just because there is no direct object that could move up to the subject position.

In this connection, it is worth considering the historical development of the "time"-away construction and the continuative or iterative aspectual away. As pointed out by the other anonymous reviewer, the "time"-away construction and the continuative aspectual away seem to appear in the $16^{\text {th }}$ century. The relevant examples are taken from the OED:

(99) a. What shall I do now to pass away the day?

b. I with ale, and ale with me, wag away.

(1550, Lusty Juventus)

(1562, The Proverbs and Epigrams of John Heywood)

If this is correct, then it would mean that the continuative aspectual away had developed in the $16^{\text {th }}$ century, which is much earlier than what we have found in the corpus data. Even though this usage is obsolete nowadays, what is interesting here is that it might be possible to analyze that the continuative aspectual away may have a relationship with the "time"-away construction. It might be the case that, like the Dutch example in (95), the adverbial PP away the day 
in (99a) expressing the duration of the action denoted by the verb pass, underwent reanalysis so that the NP the day ended up with expressing the duration of the action denoted by the phrasal verb pass away. Even though it is worth pursuing the relationship between the "time"-away construction and the continuative aspectual away, whether or not this speculation is correct is an issue that I will leave open for future investigation. ${ }^{14}$

\section{Acknowledgments}

This is a substantially revised version of the paper presented at a symposium held at Tohoku University on May 2013. I would like to thank Akiko Nagano, Hiroyuki Nawata, Yoshiki Ogawa, Robert Staehlin, and the audience at the workshop. I am also indebted two anonymous reviewers for useful comments and suggestions on earlier version of this paper. This work is supported in part by a Grant-in-aid for Scientific Research (C) (No. 24520526). All remaining errors are mine.

\section{Notes}

1. In this sense, the present analysis shares an intuition with Nicol (2002), who argues that there are two underlying syntactic position of a particle, which depends on the semantics of the particle. However, my analysis differs from Nicol (2002) in that he did not mention particles with the aspectual meaning.

2. The conative construction also shows atelic properties, as pointed out by Ramchand (2008) and MacDonald (2008).

3. As pointed out by an anonymous reviewer, if this scenario is correct, one may wonder whether a verb has changed from unergative to transitive, which is the opposite direction of grammaticalization (valency reduction). However, we would need to speculate that the verb has two variants (unergative and transitive), if we assume McIntyre's (2004) analysis on resultatives is correct.

4. I am indebted to an anonymous reviewer for providing an insightful comment on the structure (31).

5. One may wonder what happens if the internal argument of the accomplishment verbs is omitted because of the unspecified object deletion. The following data indicates that the accomplishment verbs with the object deletion show both telic as well as atelic. It might suggest that the telicity is determined by what is missing in (i) and (ii), as shown in (iii) and (iv).

(i) John ate in ten minutes.

(ii) John ate for 1 hour.

(Higginbotham (2007))

(iii) John ate the pasta in 10 minutes.

(Alexiadou, Schäfer, Spathas (2013).

(iv) John ate porridge for 10 minutes.

6. It does not necessarily mean that the continuative or iterative away is not compatible with the verbs with the unspecified object deletion. As pointed out by an anonymous reviewer, the following example may indicate the usage of the continuative or iterative away with the unspecified object deletion:

(i) Georgiana had a good appetite: she ate away with a gusto and eyed her father amusedly.

It seems to me that the particle away seems to be ambiguous: it could also have the completive meaning. In order to avoid this complication, in this paper, the particle away with the conative construction is regarded as the continuative or iterative away.

7. FREQ and PER MIL indicate the number of the occurrence of the frequency per million words, and a search item during a period during the period, respectively.

8. See 5.4. for the reason why the verb chew is treated as an activity verb.

9. See also section 5.4 for the reason why these verbs are classified as activity verbs.

10. Other usages of the intransitive eat away are shown below:

(i) It's good to eat away from home.

(ii) ... there was eating away steadily.

(1937, Harpers Magazine)

(1939, All Your Born Days)

In (i), it seems that away is connected with the preposition from, so that it is not a good example of the particle usage of away. On the other hand, the particle in (ii) seems to indicate the aspectual usage of away, but it was not included in the table (70).

11. As pointed out by an anonymous reviewer, the verb wash has the intransitive usage, which is seemingly reflexive, as shown in (i):

(i) John washed (himself).

As for the telicity, the verb wash is compatible with the 'for X-time' adverbials as well as 'in X-time' adverbials, even though the object is missing.

(ii) John washed (himself) in/for 5 minutes. 
(Alexiadou, Schäfer and Spathas (2013))

12. The conative construction with wash away can also be found by Google search.

(i) The unforgiving sea was washing away at the beach, pulling it and dragging it back... and endless rhythm... (http://www.gaiaonline.com/guilds/viewtopic.php?t=5158227\&page=9)

13. Other examples that can be found by Google search are as follows:

(i) Her face twisted up in pain; he was certain that the fluid was burning away at her skin.

(The Path into Darkness)

(ii) His whole body seemed to be on fire, a slow, smoldering pain that was burning away at him from the inside the way the ice of his dream had chilled him.

(Magic's Pawn)

14. The relevant examples can be found in 1820s through the COHA search, which is shown below:

(i) What shall I do, thought I, then, to pass away the time till ten.

(1827, Jane Talbot)

\section{REFERENCES}

[1] Akimoto, Minoji (1999) "Collocations and Idioms in Late Modern English," Collocational and Idiomatic Aspects of Composite Predicates in the History of English, ed. by Laurel J. Brinton and Minoji Akimoto, 207-238, John Benjamins, Amsterdam/Philadelphia.

[2] Alexiadou, Artemis, Florian Schäfer and Giorgos Spathas (2013) "Delimiting Voice in Germanic: on Object Drop and Naturally Reflexive Verbs," An abstract for Comparative Germanic Syntax Workshop 28.

[3] Ando, Sadao, ed. (2011) Comprehensive Dictionary of English Idioms and Phrasal Verbs, Sanseido, Tokyo.

[4] Aoki, Hiroshi (2010) Gokeisei kara Mita Nihon Bumposi (History of Japanese grammar from Word Formation), Hituzi Syobo, Tokyo.

[5] Asakawa, Teruo (2003) "Keizoku, Hanpuku no away ni Tuite (On Continuative and Repetitive away)," The Rising Generation, 149. 4, 229-231.

[6] Bolinger, Dwight (1971) The Phrasal Verb in English, Harvard University Press, Cambridge, Mass.

[7] Booij, Geert (2002) “Separable Complex Verbs in Dutch,” Verb-Particle Explorations ed. by Nicole Dehé, Ray Jackendoff, Andrew McIntyre and Silke Urban, 21-41, Mouton de Gruyter, Berlin/New York.

[8] Brinton, Laurel J. (1985) "Verb Particles in English: Aspect or Aktionsart?," Studia Linguistica 39(2), 157-68.

[9] Brinton, Laurel J. (1988) The Development of English Aspectual Systems: Aspectualizers and Post-verbal Particles, Cambridge: Cambridge University Press.

[10] Bruening, Benjamin (2010) Subject Restriction, Particle Verbs, and Comsumption Verbs. a blog at http://lingcomm. blogspot.jp/2010/05/subject-restrictions-particle-verbs-and.html.

[11] Bybee, Joan, Revere Perkins, and William Pagliuca (1994) The Evolution of Grammar: Tense, Aspect, and Modality in the Languages of the World, The University of Chicago Press, Chicago.

[12] Cappelle, Bert (2005) Particle Patterns in English: A Comprehensive Coverage, Ph.D. Dissertation, University of Leuven.

[13] Chomsky, Noam (1957) Syntactic Structures, Mouton, The Hague.

[14] Cinque, Guglielmo (1999) Adverbs and Functional Heads, Oxford University Press, Oxford.

[15] Cinque, Guilielmo (2006) Restructuring and Functional Heads, The Cartography of Syntactic Structures, vol. 4, Oxford Unversity Press, New York.

[16] Crãiniceanu Ilinca, and Ileana Baciu (2009) "Explaining the (A)telicity Property of English Verb Phrases," Acta Universitatis Sapientiae, Philologica, vol. 1, no. 2, 197-211.

[17] Dehé, Nicole, Ray Jackendoff, Andrew McIntyre and Silke Urban (2002) Verb Particle Explorations, Berlin/New York: Mouton de Gruyter.

[18] Den Dikken, Marcel (1995) Particles: On the Syntax of Verb-Particle, Triadic, and Causative Constructions, Oxford: Oxford University Press.

[19] Dixon, R.M. (1991) A New Approach to English Grammar on Semantic Principles, Clarendon Press, Oxford.

[20] Dowty, David (1989) "On the Semantic Content of the Notion "Thematic Role"," Properties, Types and Meaning, Vol. 2: Semantic Issues, ed. by Gennara Chierchia, Barbara Partee, and Raymond Turner, 69-129, Kluwer, Dordrecht.

[21] Emonds, Joseph E. (1985) A Unified Theory of Syntactic Categories, Foris, Dordrecht.

[22] Folli, Raffaella and Haidi Harley (2005) "Consuming Results in Italian and English: Flavors of v," Aspectual Inquiries, ed. by Paula Kempchinsky, Roumyana Slabakova, 95-120, Springer, Dordrecht.

[23] Fraser, Bruce (1976) The Verb-Particle Combination in English, Academic Press, New York.

[24] Fujita, Koji and Masumi Matsumoto (2005) Lexical Items (I): Verbs, Kenkyusha, Tokyo.

[25] Fukuda, Shin (2012) “Aspectual Verbs as Functional Heads: Evidence from Japanese Aspectual Verb," Natural Language and Linguistic Theory 30:4, 965-1026.

[26] Goldberg, Adele E. (2001) "Patient Arguments of Causative Verbs Can Be Omitted: the Role of Information Structure in Argument Distribution," Language Sciences 34(4-5), 503-24.

[27] Higginbotham, James (2007) "Remarks on Compositionality," The Oxford Handbook of Linguistic Interfaces, ed. by Gillian Ramchand and Charles Reiss, 425-444, Oxford University Press, Oxford.

[28] Hiltunen, Risto (1983) The Decline of the Prefixes and the Beginnings of the English Phrasal Verb: The Evidence from some Old and Early Middle English Texts, Ylipistro, Turks.

[29] Hoekstra, Teun (1988) "Small Clause Results," Lingua 74: 101-139.

[30] Ishizaki, Yasuaki (2010) "Some Notes on the Grammaticalization of away," Synchronic and Diachronic Approaches to the 
Study of Language: A collection of Papers Dedicated to the Memory of Professor Masachiyo Amano, ed. by Hirozo Nakano, Masayuki Ohkado, Tomoyuki Tanaka, Tomohiro Yanagi, and Azusa Yokogishi, 71-83, Eichosha Phoenix, Tokyo.

[31] Ishizaki, Yasuaki (2012) "Kudoosi no Bumpooka to Idiomuka (Grammaticalization and Idiomaticalization of Phrasal Verbs)," Bumpooka to Koobunka (Grammaticalization and Constructionization), ed. by Minoji Akimoto and Osamu Maeda, 189-223, Hituzi Syobo, Tokyo.

[32] Jackendoff, Ray (1997a) "Twistin' the night away," Language 73(3), 534-59.

[33] Jackendoff, Ray (1997b) The Architecture of the Language Faculty, MIT Press, Cambridge, Mass.

[34] Jackendoff, Ray (2002) "English Particle Constructions, the Lexicon, and the Autonomy of Syntax," Verb Particle Explorations, ed. by Dehé et al., 67-94, Mouton de Gruyter, Berlin/New York.

[35] Johnson, Kyle (1991) “Object positions," Natural Language and Linguistic Theory 9, 577-636.

[36] Kageyama, Taro (2012) "Doosi+Doosi gata Fukugoodoosi Kenkyuu no Genjo (The Current Status of the Study of Verb+Verb Complex Verbs)," a paper read at Syntactic, Semantic, and Morphological Characteristics of the Japanese Lexicon, September $24^{\text {th }}, 2012$, Tohoku University.

[37] Krifka, Manfred (1986) Nominalreferenz und Zeitkonstitution. Zur Semantik von Massentermen, Individualtermen, Aspektklassen, Ph. D. dissertation, The University of Munich.

[38] Krifka, Manfred (1992) "Thematic Relations as Links between Nominal Reference and Temporal Construction," Lexical Matters, ed. by Ivan Sag and Anna Szabolcsi, 29-53, CSLI.

[39] Levin, Beth (1993) English Verb Classes and Alternations: A Preliminary Investigation, University of Chicago Press, Chicago.

[40] Levin, Beth and Malka Rappaport Hovav (1995) Unaccusativity, MIT Press, Cambridge, Mass.

[41] Los, Bettelou, Corrien Blom, Geert Booij, Marion Elenbaas and Ans van Kemenade (2012) Morphosyntactic Change: A Comparative Study of Particles and Prefixes, Cambridge University Press, Cambridge.

[42] MacDonald, Jonathan (2008) The Syntactic Nature of Inner Aspect: A Minimalist Perspective, John Benjamins, Amsterdam.

[43] Mateu, Jaume (2002) Argument Structure, Relational Construal at the Syntax-Semantics Interface, Ph.D. Dissertation. Bellaterra.

[44] McIntyre, Andrew (2001) "Argument Blockages Induced by Verb Particles in English and German: Event Modification and Secondary Predication,” Structural Aspects of Semantically Complex Verbs, ed. by Nicole Dehé and Anja Wanner, 131-164, Frankfurt, Peter Lang, Berlin/New York.

[45] McIntyre, Andrew (2004) "Event Paths, Conflation, Argument Structure, and VP shells," Linguistics 42, 523-71.

[46] McIntyre, Andrew (2011) "Particle Verb Formation," Ms. Humboldt-Universität zu Berlin.

[47] Mittwoch, Anita (2005) "Unspecified Arguments in Episodic and Habitual Sentences," The Syntax of Aspect: Deriving Thematic and Aspectual Interpretation, ed. by Nomi Erteschik-Shir and Tova Rapoport, 237-254, Oxford University Press, Oxford.

[48] Neeleman, Ad (1994) Complex predicates, Ph.D. dissertation, Utrecht Institute of Linguistics, OTS.

[49] Nagano, Akiko (2007) Conversion and Back-Formation in English: Toward a Theory of Morpheme-based Morphology, Tokyo: Kaitakusha.

[50] Nagano, Akiko (this volume) "The Multi-Layered PP Analysis and the Prefix a- in English," Interdisciplinary Information Sciences Vol. 20, pp. 217-241, Graduate School of Information Sciences, Tohoku University.

[51] Nicol, Fabrice (2002) "Extended VP-shells and the Verb-Particle Construction," Verb Particle Explorations, ed. by Dehé et al., 164-90, Mouton de Gruyter, Berlin/New York.

[52] Niinuma, Fumikazu (2013) "Kudooshi no Toogokoozoo: Away wo Chuusin-ni (The Syntactic Structure of Phrasal Verbs: Focusing on Away)," A paper presented in a symposium at the $85^{\text {th }}$ conference of the English Literary Society of Japan, May $25^{\text {th }}$, Tohoku University.

[53] Nishiyama, Kunio (1998) "V-V Compounds as Serialization," Journal of East Asian Linguistics 7, 175-217.

[54] Nishiyama, Kunio and Yoshiki Ogawa (this volume) "Auxiliation, Atransitivity, and Transitivity Harmony in Japanese V-V Compounds," Interdisciplinary Information Sciences Vol. 20, pp. 71-101, Graduate School of Information Sciences, Tohoku University.

[55] Niwa, Yoshinobu (1991) The Function and Development of Prefixes and Particles in Three Early English Texts - The Beginning of the Phrasal Verb, vol. 1, Kinseido, Tokyo.

[56] Niwa, Yoshinobu (1995) The Function and Development of Prefixes and Particles in Three Early English Texts - The Beginning of the Phrasal Verb, vol. 2, Kinseido, Tokyo.

[57] Ogawa, Yoshiki and Fumikazu Niinuma (2011) "A Syntactic Consideration of the Transitivity Alternation and Transitivity Harmony in the Japanese V-V Compounds: With Special Reference to V+agaru and V+ageru," Linguistic Theories and Their Application: the Proceedings of the 2011 Winter International Conference on Linguistics in Seoul (WICLIS-2011) ed. by Jong-Yurl Yoon, et al., Hankookmunhwasa.

[58] Ogawa, Yoshiki and Fumikazu Niinuma (2013) "On the syntactic licensing of locative expressions in Japanese," Proceedings of GLOW in Asia IX, 2012: The Main Session, 229-244.

[59] Piñón, Christopher (1999) "Durative Adverbials for Result States," Proceedings of the $18^{\text {th }}$ West Coast Conference on Formal Linguistics, ed. by Sonya Bird, Andrew Carnie, Jason D. Haugen, and Peter Norquest, 420-433, Cascadilla Press, Somerville.

[60] Ramchand, Gillan (2008) Verb Meaning and the Lexicon: A First-Phase Syntax, Cambridge University Press, Cambridge.

[61] Ramchand, Gillian, and Peter Svenonius (2002) "The Lexical Syntax and Lexical Semantics of the Verb-Particle Construction," Proceedings of the West Coast Conference on Formal Linguistics, ed. by Line Mikkelsen and Christopher Potts, 387-400, Cascadilla Press, Somerville.

[62] Rice, Sally (1988) "Unlikely Lexical Entries," Proceedings of the Fourteenth Annual Meeting of the Berkeley Linguistics Society, ed. by Shelley Axmaker, Annie Jaisser and Helen Singmaster, 202-12, Berkeley Linguistics Society, Berkeley. 
[63] Rice, Sally (1999) "Aspects of Prepositions and Prepositional Aspect," Issues in Cognitive Linguistics, ed. by Leon de Stadler and Christoph Eyrich, 225-247, Mouton de Gruyter, Berlin/New York.

[64] Ritter, Elizabeth and Sara Thomas Rosen (2001) “The Interpretive Value of Object Splits," Language sciences 23, $425-251$.

[65] Roberts Ian and Anna Roussou (2003) Syntactic Change, Cambridge University Press, Cambridge.

[66] Shimada, Yuji (1985) Kudoshi (Phrasal Verbs), Taishukan Shoten, Tokyo.

[67] Svenonius, Peter (1996) “The Optionality of Particle Shift," Working Papers in Scandinavian Syntax 57, 47-75.

[68] Svenonius, Peter (2012) "Aktionsart and Aspect in Verb-Particle Constructions," Ms. University of Troms $\varnothing$.

[69] Talmy, Leonard (1985) "Lexicalization Patterns: Semantic Structure in Lexical Forms," Language Typology and Syntactic Description, Vol. 3: Grammatical Categories and the Lexicon, ed. by Timothy Shopen, 57-149, Cambridge University Press, Cambridge.

[70] Tasnim, Minura (2013) "The Process of Polysemization of English Verb rise and its Bengali Counterpart uttha," A poster presentation at the EJSJ $6^{\text {th }}$ international spring forum, April $28^{\text {th }}$, at Tokyo University.

[71] Travis, Lisa (1994) "Event Phrase and a Theory of Functional Categories," Proceedings of 1994 Annual Conference of the Canadian Linguistics Association, Toronto Working Papers in Linguistics, 559-570.

[72] Travis, Lisa (2010) Inner Aspect: The Articulation of VP, Springer, Dordrecht.

[73] Zubizarreta, Maria and Eujeong Oh (2007) On the Syntactic Composition of Manner and Motion, The MIT Press, Cambridge, Mass. 